\title{
Insulin in Central Nervous System: More than Just a Peripheral Hormone
}

\author{
Ana I. Duarte, ${ }^{1}$ Paula I. Moreira, ${ }^{1,2}$ and Catarina R. Oliveira ${ }^{1,3}$ \\ ${ }^{1}$ CNC, Center for Neuroscience and Cell Biology, University of Coimbra, 3004-517 Coimbra, Portugal \\ ${ }^{2}$ Institute of Physiology, Faculty of Medicine, University of Coimbra, 3000-354 Coimbra, Portugal \\ ${ }^{3}$ Institute of Biochemistry, Faculty of Medicine, University of Coimbra, 3000-354 Coimbra, Portugal
}

Correspondence should be addressed to Catarina R. Oliveira, catarina.n.oliveira@gmail.com

Received 4 April 2011; Revised 12 October 2011; Accepted 23 November 2011

Academic Editor: Barbara Shukitt-Hale

Copyright () 2012 Ana I. Duarte et al. This is an open access article distributed under the Creative Commons Attribution License, which permits unrestricted use, distribution, and reproduction in any medium, provided the original work is properly cited.

\begin{abstract}
Insulin signaling in central nervous system (CNS) has emerged as a novel field of research since decreased brain insulin levels and/or signaling were associated to impaired learning, memory, and age-related neurodegenerative diseases. Thus, besides its well-known role in longevity, insulin may constitute a promising therapy against diabetes- and age-related neurodegenerative disorders. More interestingly, insulin has been also faced as the potential missing link between diabetes and aging in CNS, with Alzheimer's disease (AD) considered as the "brain-type diabetes." In fact, brain insulin has been shown to regulate both peripheral and central glucose metabolism, neurotransmission, learning, and memory and to be neuroprotective. And a future challenge will be to unravel the complex interactions between aging and diabetes, which, we believe, will allow the development of efficient preventive and therapeutic strategies to overcome age-related diseases and to prolong human "healthy" longevity. Herewith, we aim to integrate the metabolic, neuromodulatory, and neuroprotective roles of insulin in two age-related pathologies: diabetes and $\mathrm{AD}$, both in terms of intracellular signaling and potential therapeutic approach.
\end{abstract}

\section{Introduction}

Almost all cell types are responsive to insulin. However, liver, muscle, and adipose tissue are the most sensitive to the hormone [1], rendering it the most important anabolic hormone identified to date. In vertebrates, this peptide belongs to a superfamily of structurally related proteins, the insulin-related family of substances, that includes insulinlike growth factors-1 (IGF-1) and -2 (IGF-2) and relaxin [2].

Until three decades ago, insulin was considered only as a peripheral hormone, unable to cross the blood-brain barrier (BBB) and to affect the central nervous system (CNS) [35]. However, this idea was challenged after the detection of immunoreactive insulin in dog cerebrospinal fluid (CSF) [6]. Further studies provided clear evidence that insulin occurs in brain, where it may reach high levels $[7,8]$, exerting long-term trophic effects on CNS neurons [2]. Although the in vivo brain insulin levels remain controversial, they appear to be 10- to 100 -fold higher than in plasma and to change during brain development, with the highest values in late fetal and early neonatal rabbit brain (about 80-90 and $195 \mathrm{ng} / \mathrm{g}$, respectively), that decrease in the adult brain (about $32 \mathrm{ng} / \mathrm{g}$ ) [7].

Insulin present in adult CNS is primarily derived from pancreatic $\beta$-cells and is transported by CSF into the brain $[3-5,9,10]$. This insulin crosses BBB mostly via a carrier-mediated, saturable, regulatable, and temperaturesensitive active process $[4,5,9,10]$ that is limited by the barrier system formed by the tight junctions between endothelial cells [2]. Thus, it is not surprising that an acute increase in peripheral insulin levels leads to higher CSF insulin, whilst chronic peripheral hyperinsulinemia (as occurs in insulin resistance) downregulates insulin receptors (IR) at BBB, impairing insulin transport into the brain [11]. Moreover, an increase in circulating insulin has been shown to rapidly affect brain activity (independently from its systemic effects), as occurs in healthy individuals submitted to a hyperinsulinemic-euglycemic clamp [12]. Alternatively, peripheral insulin can access CNS directly through the area postrema, a circumventricular region with a "leaky" BBB that 
allows free diffusion of plasma solubles directly into this area $[13,14]$.

De novo insulin synthesis in brain has been proposed as an alternative source of insulin in CNS. This hypothesis has been supported by the detection of preproinsulin I and II mRNA in rat fetal brain and cultured neurons and also by insulin immunoreactivity in neuronal endoplasmic reticulum, Golgi apparatus, cytoplasm, axon, dendrites, and synapses [15-21]. Additionally, high levels of insulin in brain extracts [22], its presence in immature nerve cell bodies $[7,18]$, the rapid transport of peripherally injected insulin into the CSF [12], and the fact that less than $1 \%$ of the hormone crosses the BBB in dogs and rodents [23] further support the idea that insulin can be synthesized in brain. However, the unequivocal evidence supporting this hypothesis is that insulin can be synthesized in cultured rat brain neurons and released upon $\mathrm{K}^{+}$- and $\mathrm{Ca}^{2+}$ induced membrane depolarization [24]. More specifically, its synthesis seems to occur in pyramidal neurons (e.g., from hippocampus, prefrontal cortex, enthorhinal cortex, and olfactory bulb), but not in glial cells [25]. Thus, it is not surprising that insulin is highly enriched in brain cortex, olfactory bulb, hippocampus, hypothalamus, and amygdala [26]. Similarly to insulin, insulin-growth factor-1 (IGF-1) occurs also in rodent and human brain and can cross the BBB $[11,27,28]$.

Taken this together, the next obvious question regards insulin and IR physiological role(s) in brain. Herewith, we will first analyse brain IR-mediated signaling pathways and the pivotal role of insulin in brain (and peripheral) glucose metabolism, synaptic transmission, memory/learning, and neuroprotection. Then, we will focus preferentially on the protective effect of insulin against diabetes and its longterm complications in CNS, aging/longevity, and age-related neurodegenerative disorders (especially Alzheimer's disease $(\mathrm{AD}))$. Finally, we will briefly discuss the pros and cons of the potential therapeutic interest of insulin in diabetes- and age-related neurodegeneration. In fact, from the evidences presented herein, insulin appears to be a naturally occurring hormone essential for normal CNS function.

\section{Neuronal IR/IGF-1R-Mediated Signaling Pathways}

2.1. Brain IR/IGF-1R Localization. Once in brain, insulin rapidly binds to IR, which are highly abundant (but selectively distributed) throughout CNS [15, 20, 26, 29], especially in olfactory bulb, hypothalamus, cerebral cortex, cerebellum, hippocampus, and striatum $[5,9,30]$. This differential distribution of insulin and IR in brain suggests that insulin from different sources (peripheral or local) may reach IR from distinct brain regions to initiate neuronal signal transduction [31]. Concerning intracellular localization, IR are highly abundant in neurons (with high protein expression in cell bodies and synapses) and less abundant in glia [32-36]. Similarly, IGF-1 receptors (IGF-1R) were detected throughout neurons and glia [37], particularly in hippocampus, amygdala, parahippocampal gyrus, cerebellum, cerebral cortex, and caudate nucleus, being less abundant in substantia nigra, red nucleus, white matter, and cerebral peduncles [15].

2.2. Brain IR/IGF-1R Structure and Signaling Pathways. IR and IGF-1R are tetrameric glycoproteins that belong to the receptor tyrosine (Tyr) kinase superfamily, composed of two $\alpha(120-135 \mathrm{kDa})$ and two $\beta(95 \mathrm{kDa})$ subunits [2, 38-40]. Brain IR subunits differ from peripheral ones by the slightly lower molecular weight and by the absence of downregulation after exposure to high insulin levels [20, 41, 42]. Besides IR and IGF-1R, the Tyr kinase superfamily comprises also human insulin receptor-related protein, Drosophila homolog of IR and mollusc IR-related protein, suggesting that their features have been highly conserved throughout evolution [2]. Interestingly, two different types of IR have been found in mammalian brain: a "peripheral-" like type (with lower density in glia cells) and a neuron-specific type (highly expressed in neurons) [11]. Due to structural and functional homology, insulin and IGF-1 can bind to (and activate) both IR and IGF-1R, with insulin binding to the IR with higher affinity $(<1 \mathrm{nM})$ than IGF-1 (100-500-fold lower affinity), whereas IGF-1R preferentially binds IGF-1 ( $<1 \mathrm{nM})$ as compared to insulin (100-500-fold lower affinity) [43]. Once bound to $\alpha$ subunits of the neuronal IR or IGF-1R, insulin (or IGF-1) promotes autophosphorylation of the $\beta$ subunit at Tyr residues 1158, 1162, and 1163, triggering its intrinsic Tyr kinase activity [5, 39, 40, 44-46] and phosphorylating insulin receptor substrate (IRS) docking proteins (IRS1-4) at Tyr residues [1]. Then, Src homology2 (SH2) domain-containing signaling molecules (namely, the p85 regulatory subunit of phospatidylinositol 3-kinase $(\mathrm{PI} 3 \mathrm{~K}))$ are recruited and activate the catalytic subunit of $\mathrm{PI} 3 \mathrm{~K}$, as well as the growth factor receptor-bound protein 2 (Grb-2) [5, 40, 44, 46]. As a consequence, two major signaling pathways can be activated: the PI3K/Akt/glycogen synthase kinase-3 $\beta$ (GSK-3 $\beta$ ) and the Ras/Raf-1/extracellular signal-regulated kinases (ERK1 and ERK2, ERK1/2) [5, 39, 40, 46].

2.3. PI3K/Akt Signaling Cascade. After binding of the $\mathrm{p} 85$ $\mathrm{SH} 2$ domain to the phosphorylated Tyr of active IRS, PI3K becomes active and p110 inhibition is relieved, allowing translocation of active $\mathrm{PI} 3 \mathrm{~K}$ to plasma membrane and subsequent formation of PI-3, 4, 5-trisphosphate, and PI3,4-bisphosphate. Then, these molecules bind to and recruit downstream signaling proteins containing pleckstrin homology domains. Amongst them, the serine (Ser)/threonine (Thr) kinase Akt can be recruited to the plasma membrane [30, 40, 46-48] and phosphorylated by protein kinase 3phosphoinositide-dependent protein kinase-1 [44, 46, 49]. Once activated, Akt detaches from plasma membrane and translocates into cytosol and nucleus [46], where it phosphorylates target proteins at Ser and Thr residues [4]. These target proteins include the proapoptotic Bad (inactivated when phosphorylated at Ser136), caspase-9 (inhibited by phosphorylation at Ser196), and GSK-3 [4]. Thus, Akt activation inhibits apoptosis [4]. 
Of relevance in this signaling pathway is the GSK-3 $\beta$, a Ser/Thr protein kinase that becomes inactive upon Aktmediated phosphorylation at the N-terminal Ser9, initiating multiple physiologic effects $[39,50-53]$. GSK-3 $\beta$ is negatively regulated also by $\mathrm{PKC}$ and $\mathrm{c}$-AMP-dependent protein kinase (PKA) (which are also activated by insulin or IGF-1) [54,55]. Depending on the cellular context, GSK- $3 \beta$ can be targeted to different intracellular locations (e.g., cytosol, mitochondria, or nucleus) to easily access its substrates [56]: active GSK-3 $\beta$ (Ser9 dephosphorylated) appears mostly in nuclei, mitochondria, and membrane lipid rafts (detergent-resistant plasma membrane microdomains involved in signal transduction), while inactive GSK-3 $\beta$ is mostly cytosolic [57]. Besides Ser9 dephosphorylation, GSK$3 \beta$ can be also activated by phosphorylation at Tyr216, and, although this mechanism remains unclear, changes in intracellular $\mathrm{Ca}^{2+}$ or Fyn (a member of the Src Tyr kinase family) appear to be involved $[58,59]$. The inhibition of GSK $3 \beta$, occurring after PI3K inhibition, has been described to prevent apoptosis, while overexpression of a constitutively active GSK-3 $\beta$ resulted in PC12 cell death [60-62]. Interestingly, Lin et al. [63] described that maintenance of phospho-GSK-3 $\beta$ levels, after transient activation of PI3K/Akt signalling, prevented apoptosis induced by hydrogen peroxide $\left(\mathrm{H}_{2} \mathrm{O}_{2}\right)$ in neural stem cells. Moreover, we previously showed that insulin prevented neuronal IR/IGF$1 \mathrm{R}$ inactivation upon oxidative stress and, by inhibiting GSK-3 $\beta$ (via PI-3K/Akt activation), insulin stimulated the synthesis of proteins involved in neuronal antioxidant defence, glucose metabolism, and antiapoptotic mechanisms [64]. Although the mechanisms underlying GSK-3 $\beta$-induced apoptosis remain unclear, decreased CREB-mediated expression of Bcl-2 [65, 66], mitochondrial cytochrome c release and caspase activation (either via the intrinsic pathway or via translocation of the apoptosis-inducing factor, AIF) [67-70], phosphorylation and downregulation of heat shock proteins (e.g., heat shock factor-1) may be involved [67].

Besides GSK-3 $\beta$, IGF-1-induced activation of Akt also phosphorylates and inhibits FoxO3, which is retained in cytoplasm by the 14-3-3 protein. As a result, nuclear translocation of FoxO3 is blocked, as well as its subsequent deleterious targeting of nuclear genes, thus promoting hippocampal and cerebellar granule neuronal survival [49, 71, 72]. This FoxO3 inhibition was also shown to impair Bim transcription in cerebellar granular neurons, contributing to the antiapoptotic effect of IGF-1 [72, 73]. Akt may also phosphorylate nuclear factor $-\kappa \mathrm{B}(\mathrm{NF}-\kappa \mathrm{B})$ either directly $[74,75]$ or via IKK-induced inhibitory protein of $\kappa \mathrm{B}(\mathrm{I} \kappa \mathrm{B})$ phosphorylation at Ser32 (with the concomitant disintegration of the $\mathrm{p} 65-\mathrm{NF}-\kappa \mathrm{B} / \mathrm{I} \kappa \mathrm{B}$ complex, translocation of p65-NF- $\kappa \mathrm{B}$ into the nucleus, and its heterodimerization with other $\mathrm{NF}-\kappa \mathrm{B}$ members for transcriptional regulation) $[76,77]$. Importantly, NF- $\kappa \mathrm{B}$ activation has been shown to increase $\mathrm{Cu} / \mathrm{Zn}$-superoxide dismutase (SOD) expression and MnSOD levels after $\mathrm{H}_{2} \mathrm{O}_{2}$ and amyloid beta $(\mathrm{A} \beta)$ treatment, protecting against oxidative stress and apoptosis in PC12 and NT2 cells, respectively [77, 78]. Alternatively, PI-3K/Akt activation may promote neuronal and glial antioxidant defences by stimulation of the Nrf-2/antioxidant responsive element (ARE) [79].

Another target for insulin-induced PI-3K/Akt pathway is CREB, which, upon phosphorylation at Ser133, enhances mitochondrial membrane potential $\left(\Delta \Psi_{m}\right)$, intracellular ATP levels, $\mathrm{NAD}(\mathrm{P}) \mathrm{H}$ redox state, and hexokinase activity, that is, improves adult neuronal glucose metabolism and axonal outgrowth [80]. Interestingly, this Akt-mediated modulation of neuronal mitochondrial function and caspase activity has been correlated with changes in Bcl-2 expression (and its interaction with $\mathrm{Bad}$ ) and/or with increased glucose transporter-1 (GLUT1) expression (and stimulation of glycolysis and protection against mitochondrial permeability transition pore opening and cytochrome c release) $[49,80]$. This may, at least partially, constitute an explanation for the apoptotic cell death that arises from the loss of neurotrophic support and subsequent depletion of PI3K/Akt signaling [80].

2.4. SHC/ERK1/2 Signaling Pathway. ERK1/2 forms a parallel branch to PI3K signaling. After phosphorylation of IR, the adapter protein SHC (Src homology-2 domaincontaining) binds to IR and Grb2 is attracted to bind to SHC via its $\mathrm{SH} 2$ domains, thus activating the ERK1/2 signaling pathway. SH3 domains are other Grb2 domains that interact with guanine nucleotide exchange son of sevenless (SOS) protein, stimulating the exchange of GDP for GTP at Ras, which becomes active and then recruits the Ser/Thr kinase Raf. Subsequent activation of MEK (or MAP2K, mitogenactivated protein kinase kinase) leads to phosphorylation (and activation) of ERK1/2 on Thr and Tyr residues [52, 8183], culminating in activation of several transcription factors that control gene expression (e.g., Ets-like protein-1 (Elk-1) and c-Myc) [46].

Interestingly, ERK1/2 activation was originally described to play an antiapoptotic role in neurons via phosphorylation of Bad at Ser112 [84, 85]. Conversely, others showed the involvement of active ERK1/2 in synaptic plasticity and cell death [86-89], especially after oxidative stress [90] and Nmethyl $D$-aspartate (NMDA) receptor-mediated excitotoxicity [87].

Traditionally, insulin signaling through PI3K-dependent pathway was considered as functionally separated from ERK- or MAPK-dependent signals, with PI3K controlling metabolism, while the mitogenic role was related with ERK1/2 [91]. However, others proposed that some cross-talk may occur between both signaling pathways, with Raf being the possible link, at least in glutamate-induced oxidative stress [82]. This cross-talk may have an anti-apoptotic role through Bad phosphorylation at Ser136 [92]. Interestingly, Subramaniam et al. [88] showed that ERK1/2 could be inhibited by IGF-1 via PI3K-dependent Raf phosphorylation at Ser259, thus protecting cerebellar granule neurons from cell death. So this could constitute an alternative pathway (to PI3K/Akt-induced phosphorylation of Bad, caspases and FoxO3) to promote neuronal survival [46].

Besides PI3K/Akt and ERK1/2 signaling pathways, insulin has also been described to protect against neuronal and non-neuronal apoptosis via activation of MAPK 
signaling [93, 94] (namely, p38 MAPK) and suppression of caspase-3 activity [95]. This was further confirmed by other studies showing that c-Jun N-terminal kinase (JNK) downregulation promoted cell survival $[96,97]$. Activation of p38 MAPK by insulin/IGF-1 was also shown to stimulate glucose transport [98-102] and antioxidant-related genes in nonneuronal cells submitted to oxidative stress [103]. Surprisingly, little or no effect on MAPK activation occurred upon insulin/IGF-1 administration in embryonic dorsal root ganglion or adult sensory neurons $[80,104]$.

\section{Role of Insulin and IGF-1 in the Brain}

3.1. Glucose Metabolism. Taken together, we can infer that the complexity of insulin/IGF-1-mediated IR/IGF-1R signaling pathways may play a crucial role in CNS, including regulation of brain metabolism [105-108], neuronal growth and differentiation $[16,105,109]$, or neuromodulation [105, 110-112]. Interestingly, tissue (and cellular) dependence on insulin is such that its restriction under some damaging conditions results in cell atrophy and apoptotic death [80].

The most well-known insulin effect is the regulation of peripheral glucose transport and metabolism $[2,113$, 114]. However, the precise underlying mechanisms were unravelled only in the last decade and appear to involve a major integration of nutritional and hormonal peripheral signals, mediated by specialized groups of neurons from the arcuate nucleus of the hypothalamus, the glucosensing neurons [115]. These neurons respond to peripheral signals required for the regulation of ingestive behaviour and energy homeostasis. Besides insulin, such signals also include the anorexigenic peptides proopiomelanocortin (POMC) and cocaine- and amphetamine-regulated transcript (CART), as well as the orexigenic neuropeptide Y (NPY) and agoutirelated peptide (AgRP) [116]. Under supraphysiological glucose levels, brain insulin signaling activation results in hyperpolarization of glucosensing neurons, activating $\mathrm{K}_{\mathrm{ATP}}^{+}$ channels and reducing neuronal firing (probably due to the inactivation of POMC neurons), thus decreasing body weight $[39,45,116]$. Conversely, impairment of brain insulin signaling (as occurs in peripheral insulin resistance) activates JNK, phosphorylating IRS-1 at Ser/Thr and promoting a feedback inhibition of IR, thus resulting in increased body weight. This orexigenic effect is mediated by the activation of arcuate neurons containing NPY, AgRP, and GABA [39, 45, 117]. Additionally, besides controlling body weight, hypothalamic insulin also regulates hepatic glucose production, and, upon impairment of hypothalamic insulin signaling, the subsequent decrease in hepatic sensitivity to the circulating insulin stimulates hepatic glucose production $[39,118,119]$. This suggests that insulin elicits a CNS (hypothalamus)-liver axis response to regulate hepatic glucose production [118].

Although traditionally brain glucose metabolism was considered essentially insulin insensitive [120], some evidences led to the hypothesis that insulin may regulate glucose metabolism only in glia [33, 121, 122]. However, more recent studies suggested that cerebral glucose metabolism may be controlled by neuronal insulin/IR signaling pathways
$[2,80,123,124]$. This hypothesis is supported by the overlapping distributions of insulin, IR, and glucose transporters (GLUTs) isoforms 1 and 4 in selective brain regions (e.g., hippocampus and choroid plexus) [15]. Furthermore, changes in circulating insulin levels were described to modulate cerebellar GLUT4 expression [125], and hyperinsulinemia led to regional changes in glucose utilization in rodent brain [126]. But the most striking evidence for insulin-mediated brain glucose metabolism came from Bingham et al. [127], showing that fasting insulin levels stimulate global glucose metabolism maximally in human brain cortex, either directly (as in peripheral tissues) or indirectly (via insulin-stimulated neuronal activation). These authors also suggested that, if the recruitment of GLUTs to the plasma membrane and subsequent increment in glucose uptake was a direct effect of insulin, this might involve the partially insulin-sensitive glial GLUT1, since the main neuronal glucose transporter (GLUT3) is insulin insensitive.

An alternative pathway for insulin to provide energy for neurons involves inhibition of neuronal norepinephrine uptake, with subsequent activation of glial $\beta$-adrenoreceptors and glucose extrusion from glial glycogen stores, namely, in astrocytes $[2,120]$. As a result, astrocytic glycogen can be converted to glucose, which is then transported to the extracellular fluid via insulin-stimulated GLUT1, constituting an additional energy source for neurons $[2,128]$.

Taken together, these evidences suggest that any deleterious interference in the cross-talk between insulin and neuronal glucose metabolism may impair ATP synthesis and culminate in neuronal apoptosis [129]. In this regard, Wu et al. [130] showed that insulin prevented serumdeprivationinduced apoptosis in R28 rat retinal neurons, while Koo and Vaziri [131] hypothesized that insulin could also prevent oxidation of glucose transporters or stimulate antioxidant defence mechanisms in type 1 diabetic streptozotocin (STZ) rats, thus stimulating intracellular metabolism. Additionally, we reported that insulin-induced IR/IGF-1R activation and subsequent $\mathrm{PI} 3 \mathrm{~K} / \mathrm{Akt}$ signaling prevented the decrease in hexokinase-II expression, thus stimulating glycolysis upon oxidative stress in rat brain cultured neurons [64, 132]. This further supports the idea that brain is both an insulin- and glucose-sensitive tissue [133]. Conversely, other studies failed to show acute effects of insulin on glucose transport into the brain $[134,135]$.

3.2. Other Roles for Insulin in Brain: Synaptic Transmission and Memory/Learning. Some authors hypothesized that brain insulin may play other roles apart from glucose metabolism, based on the heterogenous distribution of IR in brain [15], the poor correlation between IR location and neuronal energy utilization, the insulin-independent neuronal glucose uptake, the neuromodulatory role of insulin in invertebrates, its action on neuronal norepinephrine and serotonin uptake, and its relation to NPY [2]. Among such roles, brain insulin has been proposed to increase neurite outgrowth [136, 137] and regeneration of small myelinated fibers $[2,138]$, maintain cortical, sympathetic and sensory neuronal survival during nervous system development [139, 140], stimulate neuronal protein synthesis [2], and improve 
synaptic activity and plasticity, memory formation, and storage [110], as well as neuroprotection [141-143]. In this regard, insulin administration has been shown to improve memory/learning in rats [39] and in healthy humans (after intranasal administration), without changes in peripheral glycemia $[12,144]$. Systemic insulin infusion also improved verbal memory and attention [145].

Interestingly, these results appear to correlate with high IR expression in hypothalamus and limbic system (hippocampus, pyriform cortex, and amygdala) $[12,15,115]$ and may be associated with the well-known effect of insulin on synaptic transmission (e.g., monoamines) [15, 146, 147]. At this respect, about 30 years ago, insulin was described to promote epinephrine and norepinephrine release in adrenergic terminals [148], inhibit synaptic reuptake of norepinephrine, modify catecholamine kinetics, and stimulate neuronal serotonin uptake [42, 149-152]. More recently, some authors reported that insulin modulated the expression of NMDA receptors, increasing neuronal $\mathrm{Ca}^{2+}$ influx and reinforcing synaptic communication between neurons [153], and also modulated long-term potentiation, a molecular model of learning $[126,154]$. This was further supported by insulin-mediated control of cell surface glutamate and GABA receptor density (via the modulation of receptor targeting to the membrane and endocytic internalization), thus affecting synaptic plasticity [31]. Additionally, we showed that insulin prevented the decrease in GABA and glutamate uptake and their increased extrasynaptosomal levels in rat synaptosomes after oxidative stress and/or type 2 diabetes [155, 156]. Apparently, such neuromodulatory role of insulin could arise from its direct effect on neurotransmitter transport or from decreased ATP levels and subsequent reversal of the amino acid transporters $[155,156]$, thus protecting neurons against damaging effects of excitotoxicity or oxidative stress.

3.3. The Neuroprotective Role of Insulin. Regarding this issue, we and others showed that insulin or IGF-1 attenuated both retinal and brain neuronal apoptosis induced by damaging conditions (e.g., oxidative stress) [64, 130, 157-162]. Apparently, such neuroprotection could arise from restoration of IR/IGF-1R signaling-mediated gene transcription (e.g., increased hexokinase-II and $\mathrm{Bcl}-2$ and decreased glutathione peroxidase and caspase-3 expression) [64], thus improving neuronal glucose metabolism $[1,25,132,163,164]$ and antioxidant defences [157] (Figure 1). Others proposed an alternative antiapoptotic mechanism involving IGF-1induced activation of IGF-1R/PI-3K/Akt signaling and subsequent prevention of caspase activation via phosphorylation of the survival transcription factor CREB (activated), GSK$3 \beta$ (proapoptotic), and transcription factor of the Forkhead box 1 (FoxO1, inactivated) [104, 165]. Insulin-induced antiapoptotic effect might also arise from neuronal SAPK inhibition [166]. Surprisingly, Schubert et al. [167] described that, in NIRKO mice (knocked out for neuronal IR), insulin treatment was capable to circumvent neuronal apoptosis in an IR-dependent manner. In contrast, Ryu et al. [160] failed to show protection by IGF-1 against excitotoxic or oxidative stress-induced necrosis, despite a decrement in neuronal apoptosis. Additionally, insulin induced free radical generation and lipid oxidation (leading to neuronal necrosis), in a protein-kinase-C (PKC-) dependent process $[160,168]$.

Independently of the underlying signaling pathway, insulin has been increasingly shown to play a neuroprotective role against several damaging conditions, including oxidative stress, and to mitigate neuronal apoptotic death $[1,157]$. Since some of these injuries may constitute the underlying mechanisms of brain dysfunction associated with several pathologies (e.g., diabetes, aging and age-related diseases, as Alzheimer's disease (AD)), next, we will discuss the effect of insulin under such pathologies.

\section{Protection by Insulin against Diabetes and Its Long-Term Complications in CNS}

Diabetes mellitus, one of the most common metabolic disorders, is a major disorder of insulin regulation. Diabetes has reached epidemic proportions in western countries, and, according to World Health Organization estimates, it will affect $\sim 300$ million people worldwide in 2025 , rendering diabetes an important public health concern in 21 st century [169]. This is further aggravated by the increasing prevalence of diabetes with aging, risk factors associated with modern lifestyle in developed and under development countries (e.g., higher life expectancy, obesity, sedentarism, hypertension, hyperlipidemia, and genetic factors) [170], and its severe long-term complications [171] (e.g., cardiovascular disease, renal failure, retinopathy, stroke, and peripheral and autonomic neuropathy) [84, 172].

A consequence of diabetes, mostly of type 2 diabetes, is insulin resistance and chronic peripheral hyperinsulinemia, accompanied by downregulated insulin transport into the brain and its subsequent deprivation from insulin beneficial effects [173]. Indeed, diabetes-associated disruption between insulin activity and glucose metabolism results in decreased cerebral blood flow and oxidative glucose metabolism [46, 174, 175] (which may also arise from the impaired blood-brain glucose transport) [176]. This hypothesis is supported by the downregulation of neuronal insulin signaling pathways and brain glycolytic enzymes in uncontrolled diabetes $[25,176]$ (probably due to the inhibition of IR phosphorylation) that may culminate in progressive impairment in learning, memory, and cognition [25]. However, Seaquist et al. [134] failed to show any effect of short-term hyperglycemia in glucose transport.

In previous studies, we described that, despite the apparent protection against oxidative stress in type 2 diabetic Goto-Kakizaki (GK) rat brain synaptosomes (probably due to higher plasma and brain vitamin E levels) [177], they had lower synaptosomal membrane potential and ATP/ADP levels [155]. These results were (at least partially) explained by the diabetes-related impairment of brain mitochondrial electron transfer chain, which might be exacerbated by aging and/or amyloid $\beta$ peptide $(\mathrm{A} \beta)$ [178], and were counteracted by the antioxidant coenzyme CoQ10 [179] or insulin [180]. This reinforces the involvement of oxidative stress and/or metabolic/mitochondrial dysfunction in longterm damaging effects of diabetes [178-181]. 


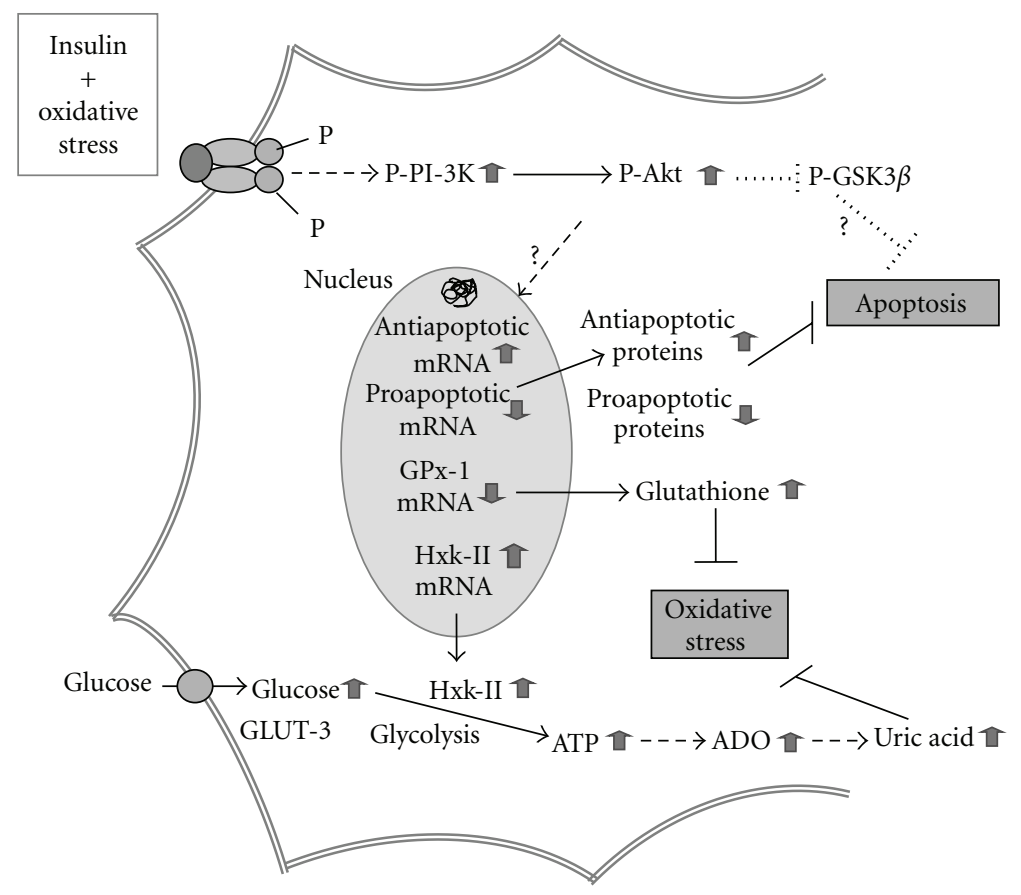

FIGURE 1: Stimulation of PI-3K/Akt signaling pathway after activation of IR/IGF-1R mediates insulin neuroprotection against damaging conditions. For example, insulin administration under oxidative stress phosphorylates IR and/or IGF-1R, which in turn activate the PI3K/Akt signaling pathway, regulating the expression of "candidate" proteins, namely, glutathione peroxidase-1 (GPx-1), hexokinase-II (HxkII), and also the antiapoptotic Bcl-2 and the proapoptotic caspase-3. Thus, oxidative stress, impaired glucose metabolism and, neuronal apoptosis are counterbalanced. Insulin also interferes with GSK-3 $\beta$ signaling, decreasing its activated form and inhibiting apoptotic neuronal death under oxidized conditions.

Although the underlying mechanisms of diabetesinduced mitochondrial dysfunction are not completely understood, it has been proposed that increased mitochondrial nitric oxide synthase (NOS) activity (and subsequent nitric oxide $\left(\mathrm{NO}^{\bullet}\right)$ production) may inhibit mitochondrial complexes III and IV and ATP synthase, either by nitrosylation or protein thiol oxidation [182]. This may lead to impairment of ATP production, decreased $\Delta \Psi_{m}$, opening of mitochondrial permeability transition pore (mPTP), and cell death [182].

Another consequence of diabetes is oxidative stress, which may arise from several mechanisms related with chronic hyperglycemia: advanced glycation endproducts (AGEs) formation, glucose autoxidation, mitochondrial dysfunction, endoplasmic reticulum stress, and impaired antioxidant defences $[183,184]$, culminating in caspasedependent neuronal death [171, 183]. Indeed, dorsal root ganglion neurons from diabetic rats displayed increased apoptotic markers (e.g., cleaved caspase-3, positive TUNEL staining [171], and PARP-1 activation [185]). Interestingly, Li et al. [183] observed that hippocampal CA1 and CA2 neuronal density from type 1 diabetic rats was lower than in type 2 diabetic animals, whilst specific markers of apoptosis (e.g., TUNEL staining, Fas and Bax expression, cytosolic AIF, expression and activity of caspases-3 and -12) and nuclear labeling of 8-hydroxy-2'-deoxyguanosine (8-OHdG) were higher, suggesting that oxidative stress could be the link to apoptotic activity in type 1 diabetes.
Besides brain glucose metabolism and oxidative stress, diabetes may also impair neurotransmission. Indeed, glutamate affinity for AMPA, but not NMDA receptors, was shown to be decreased in type 1 diabetic STZ rats [172]. Others reported an increase in taurine and GABA transport in diabetic rat retina and retinal pigment epithelium [111] and that hyperglycemia impaired glutamate release upon ischemia/reperfusion in both nondiabetic [186] and diabetic animals $[187,188]$. In this regard, we also showed that GABA levels were decreased in STZ-diabetic synaptosomes compared to control synaptosomes [189] and that insulin could modulate rat brain synaptosomal GABA and/or glutamate transport under oxidation and/or type 2 diabetes $[155,156]$.

As an antidiabetes therapy, insulin has been the best studied and more efficient pharmacological compound mainly used in the treatment of type 1 diabetes. Nevertheless, it has been also increasingly used in the treatment of type 2 diabetes noncontrolled by diet, exercise or, oral antidiabetic agents, and its use has been shown to decrease microvascular complications and mortality $[190,191]$. In this perspective, it has been increasingly suggested that all diabetic patients could be insulin treated, independently of disease progression [191]. In terms of subcellular effects of insulin on diabetes, Guyot et al. [186] reported that the insulin-induced increase in extraneuronal glutamate in type 1 diabetic STZ rats submitted to ischemia could arise from stimulation of astrocytic glucose uptake (instead of neuronal glucose uptake) with subsequent decrement in neuronal glucose 
metabolism and in the energy available for neurotransmitter uptake. This effect on neurotransmission was even more pronounced in STZ rats given a high dose of insulin, resulting in a prolonged release of aspartate, glutamate, taurine, and GABA [186]. Noteworthy, the extracellular increase in GABA as well as in the number of $\mathrm{GABA}_{\mathrm{A}}$ receptors upon insulin treatment might protect against the cytotoxic effects of released excitatory amino acids. Importantly, the damaging effects of diabetes on neurotransmission may be potentiated by impairment of $\mathrm{Ca}^{2+}$ uptake to the endoplasmic reticulum and/or mitochondria, further exacerbating neuronal excitotoxicity [172].

From the abovementioned, it seems that only diabetesrelated hyperglycemia account for the long-term damage and that, by normalizing blood glucose levels, insulin might protect against those injuries. Nevertheless, it has been also increasingly demonstrated that recurrent hypoglycemic episodes (the most common side-effect of insulin therapy) may adversely affect diabetic CNS $[84,172]$, resulting in motor incapacity, seizures, or cognitive damage, mainly in aged patients [192]. At this respect, it has been shown that recurrent hypoglycemia affected the endogenous levels of metabolites indirectly linked with brain glucose metabolism (e.g., glutamate, leading to excitotoxicity), accelerated lipolysis (increasing the formation of highly oxidizable polyunsatured fatty acids), impaired protein synthesis, ion homeostasis, and mitochondrial function, culminating in neuronal dysfunction $[120,193]$. In a recent study, our group showed that, although insulin was able to protect type 1 diabetic STZ rats (either exposed or not to $A \beta$ ) against brain oxidative stress and mitochondrial dysfunction $[180,194]$, this was not the case in STZ rat brain after an acute hypoglycemia episode [28]. This suggested that poor glycemic control might damage brain areas involved in learning and memory [28], thus limiting the analysis of insulin and hyperglycemia roles in diabetic brain [11]. Under this perspective, it is not surprising that brain requires robust neuroendocrine counterregulatory mechanisms to maintain blood glucose within a narrow, nondeleterious range.

As described before, diabetes has been widely associated with slowly progressive end-organ damage in brain [27, 195], resulting in diabetic neuropathy and/or mild to moderately impaired cognitive function, both in type 1 and type 2 diabetic patients [11]. However, clinically relevant deficits mostly occur in elderly type 2 diabetic patients, probably due to a complex interaction between diabetes and the normal brain aging [11]. Although the molecular mechanisms underlying such long-term effects of diabetes in CNS remain unclear, it has been hypothesized the involvement of AGEs formation, aldose reductase activity, oxidative stress, activation of protein kinase $\mathrm{C}$, and increased hexosamine pathway flux $[91,171,193,196,197]$. In a very recent study, Soeda et al. [198] described an increase in insulin signaling upon neuronal mutation of SH2-containing inositol 5'-phosphatase 2 (SHIP2, a negative regulator of phosphatidylinositol 3, 4, 5-trisphosphate-mediated signals) and that SHIP2 levels were also increased in type 2 diabetes $d b / d b$ mice brain. Surprisingly, SHIP2 inhibition ameliorated hippocampal synaptic plasticity and memory formation.
Conversely, when SHIP2 was overexpressed in mice, Aktmediated IR/IGF-1R signaling was impaired, the neuroprotection by insulin/IGF-1 was attenuated, and increased neuronal apoptosis and impaired memory were also reported [198].

Interestingly, insulin treatment has been described to prevent biochemical and pathological indices of peripheral sensory neuropathy in animal models of type 1 diabetes at doses that did not impact on hyperglycemia [80], suggesting that insulin therapy might not only ameliorate peripheral diabetic complications but might also improve brain function in diabetic patients [199-201]. Furthermore, this points to the existence of a link between insulin, cognitive decline and dementia, and type 2 diabetes $[27,195]$.

\section{Insulin in Aging and Longevity}

Aging can be defined as a time-dependent loss of fitness that begins after the organism attains its maximum reproductive competence [202], that is, an increased susceptibility to stress [203] that culminates in an increased incidence of chronic diseases and an exponential increase in the chance of dying [202]. Although the molecular mechanisms underlying aging remain controversial, Harman proposed, in 1968, that oxidized macromolecules accumulate with age, decreasing cell function and shortening lifespan-the Free Radical Theory of Aging [204]. If this was as simple as Harman proposed, antioxidant therapy would prevent aging-related damage to tissues. However, nutritional and genetic studies aiming to increase lifespan by boosting antioxidant defences were mostly unsuccessful [205]. Indeed, supplementation with vitamins $\mathrm{E}$ or $\mathrm{C}$ was not able to reduce mortality in several clinical trials [206, 207]. Moreover, studies involving overexpression of antioxidant enzymes (e.g., superoxide dismutase and/or catalase) in mice failed to increase lifespan, despite the decrease in oxidized macromolecules [208]. Conversely, overexpression of the peroxidase and redox-active thioredoxin 1 [209] and mitochondrial-targeted catalase [210] were shown to prolong mouse lifespan.

A parallel antiaging paradigm has been increasingly proposed, in which the effect of genetic changes or caloric restriction in insulin signaling pathway might slow the rate of living, thus decreasing metabolism and oxidative stress [211-214]. This hypothesis has been supported by studies showing that caloric or dietary restriction inhibited insulin signaling cascades that regulate glucose intake, prolonging rodent longevity [215]. However, this does not explain why the decrease in ROS levels occurs, despite the increased metabolic rate observed under such conditions [216].

More recently, it has been suggested that epigenetic factors modulated by aging (e.g., histone deacetylase family, namely, sirtuins, histone acetylases and DNA methyltransferases) impose a metabolic (redox) shift towards an increased reliance on glycolysis (instead of mitochondrial metabolism), probably mediated by age- and sedentarismrelated insulin resistance (conditions that require lower metabolic demands). Accordingly, oxidized Kelch-like ECHassociated protein 1 (Keap-1) may block NF-E2-related factor (Nrf) release to signal mitochondrial biogenesis, thus 
decreasing mitochondrial synthesis and forcing cells to rely mostly on glycolysis [205]. As a consequence, aged tissue becomes increasingly unable to cope with energy demands or stress, initiating a catastrophic cycle of oxidized membrane receptors, signaling molecules, transcription factors and epigenetic transcriptional regulators, culminating in cell death and organ failure [205]. Although the mechanisms remain unknown, it is also believed that, in this age-related oxidized environment, IR/IGF-1R may be constitutively oxidized (by free radicals and/or AGEs, which are also increased in aging [217]). This process may be due to the failure of oxidized protein tyrosine phosphatase-1b (PTP1b) to reactivate the receptor, thus limiting subsequent insulin signaling progression and impairing translocation of glucose transporters into the membrane. As a consequence, glucose levels may rise, and, although insulin production may also be stimulated, it may have no effect-the well-known insulin resistance condition that occurs in type 2 diabetes and aging $[1,205]$. Insulin resistance further potentiates the formation of AGEs, creating a damaging vicious cycle on aging brain [218].

Age-associated changes in IR signaling may also arise from increased cholesterol levels and decreased membrane fluidity (impairing lateral movements of lipid rafts) or from modification of IR internalization, reexpression, or degradation by the proteasome [1]. Noteworthy, aging has also been associated with a decrease in brain IR number and binding capacity, namely, in hippocampus, cortex, and choroid plexus [31, 219, 220].

Undissociated from aging is the longevity, which can be defined as the property of approaching the speciesspecific maximum lifespan, that is, the oldest observed age of death in the species [202]. Rather than environmental conditions, longevity depends mostly on genetics [202]. Increasing evidence points towards the idea that decreased insulin signaling pathway may promote longevity in several species, including yeast, worms, Drosophila, mice, and man [212, 221-225]. A hypothesis further supported by increased adiponectin and peroxisome proliferator-activated receptor $\gamma$-2 (PPAR $\gamma$-2) gene (two well-known insulin sensitizers) in centenarians and long-lived men, whose type 2 diabetes incidence was also dramatically decreased [226]. Additionally, single mutation of daf-2 (an IR/IGF-1R homolog) resulted in an increase in lifespan, via the nuclear translocation of the FoxO family transcription factor DAF-16 [227]. In this regard, evidences suggested that 14-3-3 molecules may complex with sirtuin 2 (Sir2) upon stress, activating nuclear FoxO/DAF-16, while the inactive FoxO/DAF-16 remained in cytoplasm upon normal insulin signaling [228]. Null mutations in Drosophila genes that encode IR or IRS homologues were shown to extend lifespan of female fruit flies [202]. Similarly, overexpression of IRS-1 in mice was shown to decrease lifespan [223], and overexpression of IRS-1, 2, 3, or 4 in adipose cells was shown to stimulate GLUT4 translocation independently from insulin [229]. Accordingly, mice lacking IRS-2 had extended lifespan [222]. Surprisingly, IR overexpression in mammary epithelial cells resulted in a tumorigenic phenotype [230], suggesting that its continuous activation upon age-related oxidative stress might not be beneficial. Recent studies suggest that reversible control of cGMP via phosphodiesterase regulation might modulate insulin production and, thus, could constitute a key regulatory messenger of lifespan extension [227].

Studies in centenarian people and caloric restriction in rodents and nonhuman primates suggested that prerequisites for longevity include (besides the above-mentioned increased insulin sensitivity and subsequent normal IR signal transduction) decreased fasting glucose and oxidative stress $[1,231]$. In line with this, decreased mitochondrial function has been suggested to, in some circumstances, increase lifespan [232]. This idea is supported by studies in the $c l k-1$ mutant worms, showing reduced respiratory, developmental and behavioural rates, but longer lifespan. Such phenomena may be related with the fact that CLK-1 is essential for ubiquinone synthesis, an important component of the mitochondrial electron respiratory chain [232]. Similar results have been described in Drosophila mutants with lower expression of electron transfer chain components in adult neurons [233] and in a mouse model with decreased activity of cytochrome c oxidase complex [234].

In this regard, type 2 diabetes appears to be, at least partially, a model for premature aging. This idea has been further confirmed by a decrease of cellular replicative senescence in diabetic subjects [1]. Thus, one of the main challenges for the next decades will be to unravel the complex interactions between aging and diabetes that result in insulin resistance, allowing the development of more efficient preventive and therapeutic strategies to overcome age-related diseases (e.g., Alzheimer's disease (AD)).

Taken together, if (1) aging is frequently related with sedentarism and (2) the organism does not require extra demands for energy, then it can survive longer on the lower energy levels resulting from glycolysis. This can occur by downregulating the mitochondrial electron transport chain components and the activities of several redox-sensitive transcription factors, enzymes, transporters, and signaling proteins (e.g., IR), as has been widely described [205]. However, the challenge becomes when the aged organism faces a stress condition.

\section{Insulin in an Age-Related Neurodegenerative Disorder: Alzheimer's Disease}

$\mathrm{AD}$ is a complex and common neurodegenerative disease that afflicted 26.6 million people worldwide in 2006, a number that can quadruplicate by 2050 [235]. Clinically, this disease has an insidious onset, typically beginning with a subtle decline in memory that progresses to global deterioration in cognitive and adaptive function [11]. Neuropathologically, is characterized by the presence of extracellular senile plaques (SP), intracellular neurofibrillary tangles (NFT), and loss of basal forebrain cholinergic neurons that innervate the hippocampus and cortex [236]. While NFTs are formed from paired helical filaments composed of neurofilaments and hyperphosphorylated tau protein, SP arises mostly after deposition of amyloid $\beta$ (A $\beta$; a 39-43 amino acid peptide derived from the proteolytic cleavage of a larger amyloid $\beta$ precursor protein (A $\beta \mathrm{PP})$ by the $\beta$ - and $\gamma$-secretases) [237]. 
The most common resulting fragments are either 40 or 42 amino acids in length $\left(\mathrm{A} \beta_{1-40}\right.$ and $\left.\mathrm{A} \beta_{1-42}\right)$ [11]. Although the initiating factor(s) for AD remain unclear, some authors suggested that they might involve intracellular (rather than extracellular) accumulation of $\mathrm{A} \beta$ [39], leading to neurite dystrophy and degeneration, postsynaptic protein loss, and eventual death of neocortical, hippocampal, and subcortical neurons $[39,44,179]$. Importantly, $\mathrm{A} \beta$ accumulation is also a common process in normal aged human, but its massive deposition in $\mathrm{AD}$ [238] may result from either an overproduction of $\mathrm{A} \beta \mathrm{PP}$, impaired $\mathrm{A} \beta \mathrm{PP}$ proteolytic processing, and/or mutations in the genes encoding for $\mathrm{A} \beta \mathrm{PP}$ or presenilins [179].

Only 5\% (or less) of all $\mathrm{AD}$ cases have an early onset, autosomal dominant familial origin, probably due to missense mutations in presenilin (PS) genes 1 or 2 in chromosomes 14 and 1 , or in the A $\beta$ PP gene in chromosome 21 [239]. Additionally, allelic abnormalities of the apolipoprotein E (APOE) gene on chromosome 19 are related with early onset and increased severity of inherited and sporadic AD [239]. On the contrary, most of AD cases (95\% or more) are sporadic in origin, aging being the main risk factor [11, 232]. Although sporadic AD is faced as a "disease" of aging, this does not necessarily imply that aging per se is a disease, and we must bear in mind that the boundaries between lateonset $\mathrm{AD}$ and "normal" aging are not absolute. This may be due to (1) increasing evidences from epidemiological, immunohistochemical, and molecular genetics studies suggesting a heterogenous etiology for $\mathrm{AD}$ [240] and (2) the fact that an unquestionable $\mathrm{AD}$ diagnosis is only possible after the patient's death, through post mortem morphological and histological brain analysis [179]. Indeed, a decline in neuropsychologic test performance, brain atrophy, neuronal loss, and plaque/tangle deposition also occur with aging in the absence of dementia [241]. Therefore, it is reasonable to consider the causal molecular events for sporadic AD within the aging spectrum, rather than distinct disease phenomena.

Although the exact pathophysiologic mechanisms underlying signal transduction abnormalities and neurodegeneration in $\mathrm{AD}$ brain remain unknown, oxidative stress and metabolic dysfunction appear to be involved [68, 242, 243]. Indeed, $\mathrm{A} \beta$ was shown to directly induce overproduction of reactive oxygen and nitrogen species and neurotoxicity [244]. This was further exacerbated by $\mathrm{A} \beta$-associated decreased plasma antioxidant defences (e.g., uric acid, glutathione, catalase, superoxide dismutase, glutathione peroxidise, and, reductase), as described by several authors [245-248]. Additionally, antioxidant supplementation (e.g., vitamin E plus vitamin $\mathrm{C}$, and donezepil, an acetylcholinesterase inhibitor, plus vitamin E) was shown to have beneficial effects in AD $[249,250]$. Similarly, vitamin E, idebenone, uric acid, or glutathione prevented $\mathrm{A} \beta$ neurotoxicity in human and rat cortical and hippocampal neurons and delayed disease progression in $\mathrm{AD}$ patients [251]. Moreover, an induction of apolipoprotein D expression (a protein that appears to function as lipid antioxidant and to extend lifespan in Drosophila) has been suggested to constitute an age-related stress-resistance mechanism in AD brains [232].
Taken together, these data unequivocally demonstrate the involvement of oxidative stress in $\mathrm{AD}$ and suggest a potential therapeutic role for antioxidant supplementation [245, 252]. However, others studies failed to show any protection induced by antioxidant treatment in AD [249, 253]. Although indirectly, the involvement of oxidative stress in $\mathrm{AD}$ pathophysiology was further reinforced by the observation of $\mathrm{AD}$ neuropil enrichment in AGEs and redox active metal ions (e.g., zinc, iron), particularly in SP, and NFT $[179,251]$ (as detected in brain cortex, hippocampus, and basal nucleus of Meynert from AD patients) [254]. To further increase the complexity on this subject, oxidative stress in $\mathrm{AD}$ may also arise from mitochondrial dysfunction, involving decreased activity of mitochondrial complex IV and decreased ATP/ADP, as revised by Moreira et al. [11]. In fact, evidences widely implicate metabolic defects in $\mathrm{AD}$, the lower brain metabolic rate being one of the best-documented abnormalities that occurs early in the pathology [255]. This may involve impaired glucose uptake and metabolism and also a slightly decreased cerebral metabolic rate of oxygen (at the beginning of $\mathrm{AD}$ ) $[256,257]$, preceding any evidence for functional impairment by neuropsychological testing or brain atrophy neuroimaging [258]. Thus, it is believed that impaired AD brain metabolism may be a cause, rather than a consequence, of neurodegeneration [259].

Although the underlying causes of reduced metabolism in $\mathrm{AD}$ are not completely understood, it has been reported that atrophy of cerebral vasculature (the major metabolic exchange surface of brain), a decrement in brain glucose transport activity, or even impaired insulin signaling might play a crucial role [11]. Indeed, Liu et al. [260] proposed that GLUT1 and GLUT3 could be downregulated in AD, thus impairing brain glucose uptake/metabolism. Additionally, several studies (including ours) showed that levels or activity of enzymes from intermediary metabolism (e.g., aconitase, glutamine synthetase, creatine kinase, pyruvate dehydrogenase, and $\alpha$-ketoglutarate dehydrogenase) were decreased in $\mathrm{AD}$ brains and cells exposed to $\mathrm{A} \beta$ [261-264]. More specifically, Bubber et al. [265] observed that changes in tricarboxylic acid cycle enzymes' activities (mainly of the pyruvate dehydrogenase complex) correlated with the clinical state, suggesting a coordinated mitochondrial alteration in $\mathrm{AD}$.

One of the most common changes in electron transport chain underlying mitochondrial dysfunction in $\mathrm{AD}$ is decreased cytochrome oxidase activity, described in such distinct AD human tissues as platelets [266, 267] and post mortem brain tissue [268, 269]. Furthermore, studies with cybrid cells demonstrated that $\mathrm{AD}$ platelet deficits in cytochrome oxidase could be transferred to cells depleted of mitochondrial DNA (mtDNA) (Rho0 cells), suggesting that mtDNA-associated mitochondrial dysfunction might play a role in AD neurodegeneration [266, 270, 271]. Valla and collaborators [272] also reported significant declines in complexes III and IV in AD lymphocyte mitochondria and a significant decline in complex IV in mild cognitive impairment lymphocyte mitochondria, suggesting that mitochondrial abnormalities could be present at the earliest symptomatic stages of the disease. Finally, enhanced mitochondria 
degradation was described in $\mathrm{AD}$, leaving behind lysosomal detritus containing non-functional mitochondrial components [261, 273].

Noteworthy, among dementia-type disorders, AD has been increasingly associated with type 2 diabetes [27, 274, 275]. Indeed, two epidemiological studies (the HonoluluAsia Aging Study, and the Rotterdam and Mayo studies) reported that type 2 diabetes increases the risk for $A D$, dependently on vascular dementia $[175,276,277]$. Furthermore, both pathologies share several common aspects, including aging-related processes, degeneration, high cholesterol levels, peripheral and CNS insulin resistance, dysfunctional IR and IR-mediated signaling, and decreased glucose transport and metabolism, despite the higher nonmetabolized glucose levels in cerebral blood [2, 5, $25,27,175,256,259,275]$. This led to the hypothesis that type-2-diabetes-mediated recurrent hyperinsulinemia/hypoglycemia episodes culminate in long-term changes in brain vasculature, neurodegeneration, and cognitive impairment, facilitating $\mathrm{AD}$ onset $[30,126,275]$. The existence of a correlation between the severity of neuritic plaques, NFT and cerebral amyloid angiopathy, and the presence of type 2 diabetes and apolipoprotein $\varepsilon_{4}\left(\mathrm{APO} \varepsilon_{4}\right)$ allele further supports this hypothesis [25, 27, 278]. On the other hand, AD patients exhibited a higher risk for developing type 2 diabetes [279], and this led to the idea that brain IR signaling might be the missing link between brain neuronal loss and pancreatic $\beta$-cell loss in both diseases $[27,279]$.

More interestingly, a recent proposal refers that $\mathrm{AD}$ can be an "insulin-resistant brain state" [11], or even a "type 3 diabetes" [12, 280-283]. This can be supported by the reports on age- and AD-related decrease in insulin mRNA and protein levels $[11,282,283]$, IR or IGF-1R expression [11, 40, 219, 284], IRS-1 and IRS-2 levels [11], markers of Tyr kinase activity (namely, active IRS-1, PI3K, and ERK1/2) [40, 175], or a reduced association of Shc with Grb2 [30]. Additionally, soluble A $\beta$ oligomers were shown to interfere with IR function, probably due to a loss of these receptors at dendrites and their increased expression in the cell soma [285], despite no changes in absolute hippocampal neuronal IR levels [286]. Accordingly, Moloney et al. [40] suggested that damaged IR-associated neurotrophic and metabolic brain functions in $\mathrm{AD}$ neurons might arise after persistent and pathological hyperactivation of the Akt-mTOR-S6K signaling pathway, increasing IRS-1 phosphorylation at Ser312 or 616 , culminating in IRS-1/2 degradation.

Concerning increased fasting plasma insulin, decreased CSF insulin levels, and/or decreased CSF/plasma insulin ratio in $\mathrm{AD}$ patients $[11,175]$, they are suggestive of insulin clearance impairment, which may elevate plasma $\mathrm{A} \beta$ levels [27, $274]$, due to the role of insulin in modulation of amyloid processing both in vivo and in vitro. In fact, brain insulin/IGF1/Akt-mediated phosphorylation/inactivation of GSK-3 $\beta$ inhibited $\mathrm{A} \beta$ production $[274,287]$ and its abnormal intracellular accumulation, probably by increasing its extracellular secretion and by accelerating its trafficking from Golgi and trans-Golgi network to the plasma membrane [39,
40]. However, under insulin resistance conditions, despite the chronic peripheral hyperinsulinemia, downregulation of brain insulin synthesis and/or transport decreased brain insulin levels [218] and its subsequent signaling cascades, culminating in increased $\mathrm{A} \beta$ levels, as in Tg2576 AD transgenic mice [288]. More recently, Freude et al. [289] reported that IRS-2 deficiency in this mouse model of $\mathrm{AD}$ decreased both $\mathrm{A} \beta \mathrm{PP}$ cleavage and $\mathrm{A} \beta$ levels in brain. Similar results were obtained upon selective neuronal disruption of IGF-1R in Tg2576 mice [289]. Alternatively, insulin/IGF-1 prevented $\mathrm{A} \beta$ accumulation by promoting its transport into $\mathrm{CNS}$ via $\mathrm{A} \beta$-binding carrier proteins (e.g., transthyretin and albumin) [27, 200, 238, 290-292], or by insulin interfering with extracellular proteolytic $\mathrm{A} \beta$ degradation via insulindegrading enzyme (IDE). This metalloprotease, that also catabolizes insulin and IGF-1, can be competitively inhibited by insulin resistance $[30,46,126,200,218,238,278]$, impairing $A \beta$ degradation, increasing its neurotoxicity and promoting $\mathrm{AD}[11,46,278]$. Noteworthy, since brain IR does not desensitize, IDE may also constitute a negative feedback loop to control insulin action [31, 46], that is, PI3K/Akt activation by insulin may upregulate IDE, which may stop subsequent signaling and promote $\mathrm{A} \beta$ clearance in hippocampal neurons [31].

Insulin and IGF-1 were also described to modulate both physiological and abnormal neuronal tau protein phosphorylation, in a process involving Akt, GSK-3 $\beta$, ERK1/2, and Cdk-5 [12, 25, 27, 30, 39, 40, 44]. Similarly, Sui et al. [57] observed that GSK-3 $\beta$ inhibition blocked specific phosphorylation of tau protein in PC12 cells. Moreover, in diabetic animals treated with insulin, a complete prevention of tau protein hyperphosphorylation was reported, probably resulting from reestablishment of brain insulin signaling [293]. This is further supported by the age-related tau protein hyperphosphorylation and CNS accumulation in both transgenic NIRKO mice (mice lacking brain/neuronal IR) [59] and IRS-2-deficient mice (in which brain IR is dysregulated) [294]. Interestingly, hyperinsulinemia in NIRKO mice [12, 167] and insulin treatment in human NT2 neurons [295] were described to decrease tau protein phosphorylation. Conversely, several authors described that in human SH-SY5Y neuroblastoma cells $[59,296]$ and rat primary cortical neurons [297], insulin exposure increased hyperphosphorylated tau protein levels, which was not transported into axons, thus accumulating and aggregating into NFTs in neuronal perikarya, and thereby promoting oxidative stress, apoptotic or necrotic death, and mitochondrial dysfunction associated with $\mathrm{AD}[30]$.

\section{Is There a Therapeutic Window for Insulin against Diabetes- and Age-Related Neurodegeneration?}

From all the above-mentioned evidences, we believe that a valuable therapeutic window for insulin against diabetesand age-related neurodegenerative disorders (e.g., AD) may exist. Under these conditions, an inadequate trophic 
support to brain may occur due to lower insulin/IGF-1 levels and/or damaged IR/IGF-1R-mediated signaling, affecting gene transcription and culminating in neurodegeneration/death, cognitive dysfunction, and, ultimately, in longterm complications (in case of diabetes) and/or in $\mathrm{AD}$ (and other dementia) [46]. Thus, those symptoms should be alleviated upon increased insulin levels, accomplished by exogenous insulin plus glucose administration (to maintain euglycemia, avoiding the deleterious effects of hypoglycemia on memory and cognition) $[30,164,175]$. Interestingly, intranasal insulin administration has been increasingly considered as a potential peripheral therapy, with the advantage of penetrating the CNS within minutes (without affecting plasma glucose or insulin levels) [298]. This can occur via extracellular bulk flow transport along olfactory and trigeminal perivascular channels, but also through more traditional axonal transport pathways, culminating in memory improvement [39, 144, 298-300]. In this regard, a very recent clinical trial from Craft et al. [301] showed that treatment of AD or mildly cognitively impaired adults with intranasal insulin stabilized or improved cognition and cerebral glucose metabolism. Similarly, direct intracerebroventricular insulin administration was shown to improve memory performance (without changes in blood insulin or glucose concentrations), but this approach poses some questions concerning its human applicability [175]. Although the use of stem cells to deliver insulin or IGF-1 into brain has been considered as a hypothetical beneficial therapy (by increasing neuronal survival and decreasing oxidative stress in the CNS), safety and efficacy issues must first be improved [30].

However, chronically high insulin levels in brain can be deleterious [46], due to (1) desensitization of PI3K pathway and inadequate responses to other trophic factors, (2) potentiation of NMDA receptors and resultant excitotoxicity, and/ or (3) competition with $\mathrm{A} \beta$ for IDE, increasing extracellular $\mathrm{A} \beta$ accumulation (meaning that excessive insulin must be removed to alleviate the competitive blockade of IDE) $[44,46]$. A therapeutical alternative could be the use of antidiabetic insulin sensitizers (e.g., thiazolidinediones) that, under hyperinsulinemia, would decrease insulin availability to the brain without affecting glycemia [46]. Unfortunately, clinical trials showed that rosiglitazone, a thiazolidinedione, decreased cognitive performance in $\mathrm{AD}$ patients $[302,303]$. Other therapeutical approaches could be (1) the small molecule insulin mimetic demethylasterriquinone $\mathrm{B}_{1}\left(\mathrm{DAQB}_{1}\right)$ that does not competitively inhibit IDE and modulates IR [304], (2) the delivery of insulin antibodies, or (3) insulin-inhibiting peptides into the brain [46]. Increased CNS IDE levels (via gene therapy or IDE infusion) would be also of therapeutical interest but is less practical. Given that activated PI3K/Akt inhibits GSK-3 $\beta$ and subsequent $A \beta$ production and tau protein hyperphosphorylation (as well as increased $\mathrm{A} \beta$ clearance via stimulation of transthyretin and IDE), another strategy could be the improvement of insulin signaling $[44,46,218]$. In line with this, the use of GSK-3 $\beta$ inhibitors could be attractive, but it might also impair several vital physiological targets of this kinase or have no impact on other critical components of the neurodegenerative cascade $[30,218]$.

\section{Conclusion}

In the last three decades, brain insulin signaling has faced a novel and increased interest in neuroscience research, either in its signaling pathways and/or as a promising therapy against diabetes and age-related neurodegenerative disorders (e.g., AD). From the first studies recognizing the abundance of insulin and IR in brain to its potential involvement in numerous neurodegenerative diseases associated with diabetes (particularly type 2 diabetes) and aging mediated less than 20 years. Indeed, in 1999, Halter described that elderly people have impaired insulin sensitivity, which might account for by the slight age-related increase in fasting glucose levels and the delay in return to normal glucose levels after an oral glucose tolerance test. However, more than 10 years later, the elucidation on whether the origin of this insulin resistant state relies on aging per se or on external, lifestyle factors remains a matter of debate. In this regard, one of the main challenges for the next decades will be to unravel the complex interactions between aging and diabetes that underlie insulin resistance, allowing the development of more efficient preventive and therapeutic strategies to overcome age-related neurodegenerative diseases.

Concerning $\mathrm{AD}$, a recent hypothesis points towards the idea that $\mathrm{AD}$ is the "brain-type diabetes." This is supported by decreased number or binding capacity of brain IR in both $\mathrm{AD}$ patients and mouse models, increased risk for type 2 diabetes in $\mathrm{AD}$ patients (and vice versa), and the accumulation of hyperphosphorylated tau in the CNS of IRS-2-disrupted mice, a model of type 2 diabetes. Thus, restoring insulin levels and/or its receptor-mediated signaling cascades (without affecting blood glucose levels) constitute a potentially interesting therapeutic strategy against $\mathrm{AD}$, due to the inhibition of $A \beta$ production (and its increased clearance) and tau protein hyperphosphorylation, two wellknown hallmarks of the pathology.

More recent studies focused on the importance of insulin/IR signaling in increased longevity. However, the results remain highly controversial.

In summary, in CNS, rather than just an "acquired" peripheral hormone, insulin appears to be a naturally occurring peptide of the outmost importance.

\section{Acknowledgments}

The authors are grateful to Fundação para a Ciência e a Tecnologia (FCT, Project PTDC/SAU-TOX/117481/2010), Portugal, Programa de Estímulo à Investigação da Faculdade de Medicina, Universidade de Coimbra, Portugal (PMADSC/2011), and European Social Fund (fellowship reference SFRH/BPD/26872/2006 to A. I. Duarte) for financial support.

\section{References}

[1] T. Fulop, A. Larbi, and N. Douziech, "Insulin receptor and ageing," Pathologie Biologie, vol. 51, no. 10, pp. 574-580, 2003. 
[2] R. J. Schulingkamp, T. C. Pagano, D. Hung, and R. B. Raffa, "Insulin receptors and insulin action in the brain: review and clinical implications," Neuroscience and Biobehavioral Reviews, vol. 24, no. 8, pp. 855-872, 2000.

[3] Z. Laron, "Insulin and the brain," Archives of Physiology and Biochemistry, vol. 115, no. 2, pp. 112-116, 2009.

[4] A. Erol, "An integrated and unifying hypothesis for the metabolic basis of sporadic Alzheimer's disease," Journal of Alzheimer's Disease, vol. 13, no. 3, pp. 241-253, 2008.

[5] M. Salkovic-Petrisic and S. Hoyer, "Central insulin resistance as a trigger for sporadic Alzheimer-like pathology: an experimental approach," Journal of Neural Transmission, no. 72, pp. 217-233, 2007.

[6] R. U. Margolis and N. Altszuler, "Insulin in the cerebrospinal fluid," Nature, vol. 215, no. 5108, pp. 1375-1376, 1967.

[7] R. Schechter, J. Whitmire, L. Holtzclaw, M. George, R. Harlow, and S. U. Devaskar, "Developmental regulation of insulin in the mammalian central nervous system," Brain Research, vol. 582, no. 1, pp. 27-37, 1992.

[8] D. LeRoith, "CNS regulation of carbohydrate metabolism," in Advances in Metabolic Disorders, A. Szabo, Ed., vol. 10, pp. 304-340, Academic Press, 1983.

[9] J. M. Burns, J. E. Donnelly, H. S. Anderson et al., "Peripheral insulin and brain structure in early Alzheimer disease," Neurology, vol. 69, no. 11, pp. 1094-1104, 2007.

[10] W. A. Banks, "The source of cerebral insulin," European Journal of Pharmacology, vol. 490, no. 1-3, pp. 5-12, 2004.

[11] P. I. Moreira, A. I. Duarte, M. S. Santos, A. C. Rego, and C. R. Oliveira, "An integrative view of the role of oxidative stress, mitochondria and insulin in Alzheimer's disease," Journal of Alzheimer's Disease, vol. 16, no. 4, pp. 741-761, 2009.

[12] S. Freude, L. Plum, J. Schnitker et al., "Peripheral hyperinsulinemia promotes tau phosphorylation in vivo," Diabetes, vol. 54, no. 12, pp. 3343-3348, 2005.

[13] R. Sankar, S. Thamotharan, D. Shin, K. H. Moley, and S. U. Devaskar, "Insulin-responsive glucose transporters-GLUT8 and GLUT4 are expressed in the developing mammalian brain," Molecular Brain Research, vol. 107, no. 2, pp. 157-165, 2002.

[14] D. Porte, R. J. Seeley, S. C. Woods, D. G. Baskin, D. P. Figlewicz, and M. W. Schwartz, "Obesity, diabetes and the central nervous system," Diabetologia, vol. 41, no. 8, pp. 863$881,1998$.

[15] W. Zhao, H. Chen, H. Xu et al., "Brain insulin receptors and spatial memory. Correlated changes in gene expression, tyrosine phosphorylation, and signaling molecules in the hippocampus of water maze trained rats," Journal of Biological Chemistry, vol. 274, no. 49, pp. 34893-34902, 1999.

[16] R. Schechter, T. Yanovitch, M. Abboud, G. Johnson, and J. Gaskins, "Effects of brain endogenous insulin on neurofilament and MAPK in fetal rat neuron cell cultures," Brain Research, vol. 808, no. 2, pp. 270-278, 1998.

[17] S. Craft, J. Newcomer, S. Kanne et al., "Memory improvement following induced hyperinsulinemia in Alzheimer's disease," Neurobiology of Aging, vol. 17, no. 1, pp. 123-130, 1996.

[18] R. Schechter, D. Beju, T. Gaffney, F. Schaefer, and L. Whetsell, "Preproinsulin I and II mRNAs and insulin electron microscopic immunoreaction are present within the rat fetal nervous system," Brain Research, vol. 736, no. 1-2, pp. 16-27, 1996.

[19] R. Schechter, H. F. Sadiq, and S. U. Devaskar, "Insulin and insulin mRNA are detected in neuronal cell cultures maintained in an insulin-free/serum-free medium," Journal of Histochemistry and Cytochemistry, vol. 38, no. 6, pp. 829836, 1990.

[20] M. Adamo, M. K. Raizada, and D. LeRoith, "Insulin and insulin-like growth factor receptors in the nervous system," Molecular Neurobiology, vol. 3, no. 1-2, pp. 71-100, 1989.

[21] R. Schechter, L. Holtzclaw, F. Sadiq, A. Kahn, and S. Devaskar, "Insulin synthesis by isolated rabbit neurons," Endocrinology, vol. 123, no. 1, pp. 505-513, 1988.

[22] J. Havrankova, J. Roth, and M. J. Brownstein, "Concentrations of insulin and of insulin receptors in the brain are independent of peripheral insulin levels. Studies of obese and streptozotocin-treated rodents," Journal of Clinical Investigation, vol. 64, no. 2, pp. 636-642, 1979.

[23] W. A. Banks and A. J. Kastin, "Differential permeability of the blood-brain barrier to two pancreatic peptides: insulin and amylin," Peptides, vol. 19, no. 5, pp. 883-889, 1998.

[24] D. W. Clarke, L. Mudd, and F. T. Boyd Jr., "Insulin is released from rat brain neuronal cells in culture," Journal of Neurochemistry, vol. 47, no. 3, pp. 831-836, 1986.

[25] S. Hoyer, "Memory function and brain glucose metabolism," Pharmacopsychiatry, vol. 36, no. 1, pp. S62-S67, 2003.

[26] J. Havrankova, J. Roth, and M. Brownstein, "Insulin receptors are widely distributed in the central nervous system of the rat," Nature, vol. 272, no. 5656, pp. 827-829, 1978.

[27] L. Li and C. Hölscher, "Common pathological processes in Alzheimer disease and type 2 diabetes: a review," Brain Research Reviews, vol. 56, no. 2, pp. 384-402, 2007.

[28] S. Cardoso, M. S. Santos, R. Seiça, and P. I. Moreira, "Cortical and hippocampal mitochondria bioenergetics and oxidative status during hyperglycemia and/or insulin-induced hypoglycemia," Biochimica et Biophysica Acta, vol. 1802, no. 11, pp. 942-951, 2010.

[29] G. A. Werther, A. Hogg, B. J. Oldfield et al., "Localization and characterization of insulin receptors in rat brain and pituitary gland using in vitro autoradiography and computerized densitometry," Endocrinology, vol. 121, no. 4, pp. 1562-1570, 1987.

[30] S. M. De La Monte and J. R. Wands, "Review of insulin and insulin-like growth factor expression, signaling, and malfunction in the central nervous system: relevance to Alzheimer's disease," Journal of Alzheimer's Disease, vol. 7, no. 1, pp. 45-61, 2005.

[31] W. Q. Zhao, H. Chen, M. J. Quon, and D. L. Alkon, "Insulin and the insulin receptor in experimental models of learning and memory," European Journal of Pharmacology, vol. 490, no. 1-3, pp. 71-81, 2004.

[32] D. G. Baskin, A. J. Sipols, M. W. Schwartz, and M. F. White, "Immunocytochemical detection of insulin receptor substrate-1 (IRS-1) in rat brain: colocalization with phosphotyrosine," Regulatory Peptides, vol. 48, no. 1-2, pp. 257266, 1993.

[33] M. W. Schwartz, D. P. Figlewicz, D. G. Baskin, S. C. Woods, and D. Porte, "Insulin in the brain: a hormonal regulator of energy balance," Endocrine Reviews, vol. 13, no. 3, pp. 387414, 1992.

[34] J. L. Marks, M. G. King, and D. G. Baskin, "Insulin and insulin-like growth factors," in Molecular Biology and Physiology of Insulin and Insulin-like Growth Factors, pp. 459470, Plenum Press, New York, NY, USA, 1991.

[35] J. W. Unger, A. M. Moss, and J. N. Livingston, "Immunohistochemical localization of insulin receptors and phosphotyrosine in the brainstem of the adult rat," Neuroscience, vol. 42, no. 3, pp. 853-861, 1991. 
[36] J. L. Marks, J. Maddison, and C. J. Eastman, "Subcellular localization of rat brain insulin binding sites," Journal of Neurochemistry, vol. 50, no. 3, pp. 774-781, 1988.

[37] L. M. Garcia-Segura, J. R. Rodriguez, and I. Torres-Aleman, "Localization of the insulin-like growth factor I receptor in the cerebellum and hypothalamus of adult rats: an electron microscopic study," Journal of Neurocytology, vol. 26, no. 7, pp. 479-490, 1997.

[38] J. Schlessinger, "Cell signaling by receptor tyrosine kinases," Cell, vol. 103, no. 2, pp. 211-225, 2000.

[39] A. Wada, H. Yokoo, T. Yanagita, and H. Kobayashi, "New twist on neuronal insulin receptor signaling in health, disease, and therapeutics," Journal of Pharmacological Sciences, vol. 99, no. 2, pp. 128-143, 2005.

[40] A. M. Moloney, R. J. Griffin, S. Timmons, R. O'Connor, R. Ravid, and C. O'Neill, "Defects in IGF-1 receptor, insulin receptor and IRS-1/2 in Alzheimer's disease indicate possible resistance to IGF-1 and insulin signalling," Neurobiology of Aging, vol. 31, no. 2, pp. 224-243, 2010.

[41] N. R. Zahniser, M. B. Goens, P. J. Hanaway, and J. V. Vinych, "Characterization and regulation of insulin receptors in rat brain," Journal of Neurochemistry, vol. 42, no. 5, pp. 13541362, 1984.

[42] F. T. Boyd and M. K. Raizada, "Effects of insulin and tunicamycin on neuronal insulin receptors in culture," The American Journal of Physiology, vol. 245, no. 3, pp. C283-287, 1983.

[43] R. Conejo and M. Lorenzo, "Insulin signaling leading to proliferation, survival, and membrane ruffling in $\mathrm{C} 2 \mathrm{C} 12$ myoblasts," Journal of Cellular Physiology, vol. 187, no. 1, pp. 96-108, 2001.

[44] G. M. Cole and S. A. Frautschy, "The role of insulin and neurotrophic factor signaling in brain aging and Alzheimer's Disease," Experimental Gerontology, vol. 42, no. 1-2, pp. 1021, 2007.

[45] L. Plum, B. F. Belgardt, and J. C. Brüning, "Central insulin action in energy and glucose homeostasis," Journal of Clinical Investigation, vol. 116, no. 7, pp. 1761-1766, 2006.

[46] L. P. van der Heide, G. M. J. Ramakers, and M. P. Smidt, "Insulin signaling in the central nervous system: learning to survive," Progress in Neurobiology, vol. 79, no. 4, pp. 205-221, 2006.

[47] M. D. Bruss, E. B. Arias, G. E. Lienhard, and G. D. Cartee, "Increased phosphorylation of Akt substrate of $160 \mathrm{kDa}$ (AS160) in rat skeletal muscle in response to insulin or contractile activity,” Diabetes, vol. 54, no. 1, pp. 41-50, 2005.

[48] K. D. Niswender and M. W. Schwartz, "Insulin and leptin revisited: adiposity signals with overlapping physiological and intracellular signaling capabilities," Frontiers in Neuroendocrinology, vol. 24, no. 1, pp. 1-10, 2003.

[49] Z. C. Zhao, F. Li, and K. Maiese, "Oxidative stress in the brain: novel cellular targets that govern survival during neurodegenerative disease," Progress in Neurobiology, vol. 75, no. 3, pp. 207-246, 2005.

[50] K. G. Brywe, C. Mallard, M. Gustavsson et al., "IGFI neuroprotection in the immature brain after hypoxiaischemia, involvement of Akt and GSK3 $\beta$ ?? European Journal of Neuroscience, vol. 21, no. 6, pp. 1489-1502, 2005.

[51] S. Srinivasan, M. Ohsugi, Z. Liu, S. Fatrai, E. BernalMizrachi, and M. A. Permutt, "Endoplasmic reticulum stress-induced apoptosis is partly mediated by reduced insulin signaling through phosphatidylinositol 3-kinase/Akt and increased glycogen synthase kinase- $3 \beta$ in mouse insulinoma cells," Diabetes, vol. 54, no. 4, pp. 968-975, 2005.
[52] T. Ogata, S. Iijima, S. Hoshikawa et al., "Opposing extracellular signal-regulated kinase and Akt pathways control schwann cell myelination," Journal of Neuroscience, vol. 24, no. 30, pp. 6724-6732, 2004.

[53] N. Ibrahim, M. A. Bosch, J. L. Smart et al., "Hypothalamic proopiomelanocortin neurons are glucose responsive and express KATP channels," Endocrinology, vol. 144, no. 4, pp. 1331-1340, 2003.

[54] X. Fang, S. X. Yu, Y. Lu, R. C. Bast, J. R. Woodgett, and G. B. Mills, "Phosphorylation and inactivation of glycogen synthase kinase 3 by protein kinase A," Proceedings of the National Academy of Sciences of the United States of America, vol. 97, no. 22, pp. 11960-11965, 2000.

[55] N. Goode, K. Hughes, J. R. Woodgett, and P. J. Parker, "Differential regulation of glycogen synthase kinase- $3 \beta$ by protein kinase C isotypes," Journal of Biological Chemistry, vol. 267, no. 24, pp. 16878-16882, 1992.

[56] R. S. Jope and G. V. W. Johnson, "The glamour and gloom of glycogen synthase kinase-3," Trends in Biochemical Sciences, vol. 29, no. 2, pp. 95-102, 2004.

[57] Z. Sui, A. D. Kovács, and S. B. Maggirwar, "Recruitment of active glycogen synthase kinase-3 into neuronal lipid rafts," Biochemical and Biophysical Research Communications, vol. 345, no. 4, pp. 1643-1648, 2006.

[58] J. A. Hartigan and G. V. W. Johnson, "Transient increases in intracellular calcium result in prolonged site-selective increases in Tau phosphorylation through a glycogen synthase kinase 3 $\beta$-dependent pathway," Journal of Biological Chemistry, vol. 274, no. 30, pp. 21395-21401, 1999.

[59] M. Lesort, R. S. Jope, and G. V. W. Johnson, "Insulin transiently increases tau phosphorylation: involvement of glycogen synthase kinase- $3 \beta$ and Fyn tyrosine kinase," Journal of Neurochemistry, vol. 72, no. 2, pp. 576-584, 1999.

[60] J. F. Sanchez, L. F. Sniderhan, A. L. Williamson, S. Fan, S. Chakraborty-Sett, and S. B. Maggirwar, "Glycogen synthase kinase $3 \beta$-mediated apoptosis of primary cortical astrocytes involves inhibition of nuclear factor $\kappa \mathrm{B}$ signaling," Molecular and Cellular Biology, vol. 23, no. 13, pp. 4649-4662, 2003.

[61] M. Pap and G. M. Cooper, "Role of glycogen synthase kinase3 in the phosphatidylinositol 3-kinase/Akt cell survival pathway," Journal of Biological Chemistry, vol. 273, no. 32, pp. 19929-19932, 1998.

[62] R. J. Crowder and R. S. Freeman, "Glycogen synthase kinase$3 \beta$ activity is critical for neuronal death caused by inhibiting phosphatidylinositol 3-kinase or Akt but not for death caused by nerve growth factor withdrawal," Journal of Biological Chemistry, vol. 275, no. 44, pp. 34266-34271, 2000.

[63] H. J. Lin, X. Wang, K. M. Shaffer, C. Y. Sasaki, and W. $\mathrm{Ma}$, "Characterization of $\mathrm{H} 2 \mathrm{O} 2$-induced acute apoptosis in cultured neural stem/progenitor cells," FEBS Letters, vol. 570, no. 1-3, pp. 102-106, 2004.

[64] A. I. Duarte, P. Santos, C. R. Oliveira, M. S. Santos, and A. C. Rego, "Insulin neuroprotection against oxidative stress is mediated by Akt and GSK- $3 \beta$ signaling pathways and changes in protein expression," Biochimica et Biophysica Acta, vol. 1783, no. 6, pp. 994-1002, 2008.

[65] C. A. Grimes and R. S. Jope, "Creb DNA binding activity is inhibited by glycogen synthase kinase- $3 \beta$ and facilitated by lithium," Journal of Neurochemistry, vol. 78, no. 6, pp. 12191232, 2001.

[66] S. Pugazhenthit, A. Nesterova, C. Sable et al., "Akt/protein kinase B up-regulates Bcl-2 expression through cAMPresponse element-binding protein," Journal of Biological Chemistry, vol. 275, no. 15, pp. 10761-10766, 2000. 
[67] B. McLaughlin, K. A. Hartnett, J. A. Erhardt et al., "Caspase 3 activation is essential for neuroprotection in preconditioning," Proceedings of the National Academy of Sciences of the United States of America, vol. 100, no. 2, pp. 715-720, 2003.

[68] X. Zhu, A. K. Raina, H. G. Lee et al., "Oxidative stress and neuronal adaptation in Alzheimer disease: the role of SAPK pathways," Antioxidants and Redox Signaling, vol. 5, no. 5, pp. 571-576, 2003.

[69] R. Wang, H. Y. Zhang, and X. C. Tang, "Huperzine A attenuates cognitive dysfunction and neuronal degeneration caused by $\beta$-amyloid protein-(1-40) in rat," European Journal of Pharmacology, vol. 421, no. 3, pp. 149-156, 2001.

[70] Y. Cheng, M. Deshmukh, A. D'Costa et al., "Caspase inhibitor affords neuroprotection with delayed administration in a rat model of neonatal hypoxic-ischemic brain injury," Journal of Clinical Investigation, vol. 101, no. 9, pp. 1992-1999, 1998.

[71] C. P. Beier, J. Wischhusen, M. Gleichmann et al., "FasL (CD95L/APO-1L) resistance of neurons mediated by phosphatidylinositol 3-kinase-Akt/protein kinase B-dependent expression of lifeguard/neuronal membrane protein 35," Journal of Neuroscience, vol. 25, no. 29, pp. 6765-6774, 2005.

[72] W. H. Zheng, S. Kar, and R. Quirion, "Insulin-like growth factor-1-induced phosphorylation of transcription factor FKHRL1 is mediated by phosphatidylinositol 3-kinase/Akt kinase and role of this pathway in insulin-like growth factor-1-induced survival of cultured hippocampal neurons," Molecular Pharmacology, vol. 62, no. 2, pp. 225-233, 2002.

[73] D. A. Linseman, R. A. Phelps, R. J. Bouchard et al., "Insulinlike growth factor-I blocks Bcl-2 interacting mediator of cell death (Bim) induction and intrinsic death signaling in cerebellar granule neurons," Journal of Neuroscience, vol. 22, no. 21, pp. 9287-9297, 2002.

[74] A. S. Baldwin, "The NF- $\kappa$ B and I $\kappa$ B proteins: new discoveries and insights," Annual Review of Immunology, vol. 14, pp. 649$681,1996$.

[75] I. M. Verma, J. K. Stevenson, E. M. Schwarz, D. Van Antwerp, and S. Miyamoto, "Rel/NF- $\kappa \mathrm{B} / \mathrm{I} \kappa \mathrm{B}$ family: intimate tales of association and dissociation," Genes and Development, vol. 9, no. 22, pp. 2723-2735, 1995.

[76] G. Chen, K. A. Bower, C. Ma, S. Fang, C. J. Thiele, and J. Luo, "Glycogen synthase kinase $3 \beta$ (GSK3 $\beta$ ) mediates 6hydroxydopamine-induced neuronal death," FASEB Journal, vol. 18, no. 10, pp. 1162-1164, 2004.

[77] A. I. Rojo, M. Salinas, D. Martín, R. Perona, and A. Cuadrado, "Regulation of $\mathrm{Cu} / \mathrm{Zn}$-superoxide dismutase expression via the phosphatidylinositol 3 kinase/Akt pathway and nuclear factor- $\kappa$ B," Journal of Neuroscience, vol. 24, no. 33, pp. 73247334, 2004.

[78] S. M. Cardoso and C. R. Oliveira, "Glutathione cycle impairment mediates $\mathrm{A} \beta$-induced cell toxicity," Free Radical Research, vol. 37, no. 3, pp. 241-250, 2003.

[79] F. Li, C. Szabó, P. Pacher et al., "Evaluation of orally active poly(ADP-ribose) polymerase inhibitor in streptozotocindiabetic rat model of early peripheral neuropathy," Diabetologia, vol. 47, no. 4, pp. 710-717, 2004.

[80] T. J. Huang, A. Verkhratsky, and P. Fernyhough, "Insulin enhances mitochondrial inner membrane potential and increases ATP levels through phosphoinositide 3-kinase in adult sensory neurons," Molecular and Cellular Neuroscience, vol. 28, no. 1, pp. 42-54, 2005.

[81] I. G. Onyango, J. P. Bennett, and J. B. Tuttle, "Endogenous oxidative stress in sporadic Alzheimer's disease neuronal cybrids reduces viability by increasing apoptosis through pro-death signaling pathways and is mimicked by oxidant exposure of control cybrids," Neurobiology of Disease, vol. 19, no. 1-2, pp. 312-322, 2005.

[82] D. J. Levinthal and D. B. DeFranco, "Transient phosphatidylinositol 3-kinase inhibition protects immature primary cortical neurons from oxidative toxicity via suppression of extracellular signal-regulated kinase activation," Journal of Biological Chemistry, vol. 279, no. 12, pp. 11206-11213, 2004.

[83] M. P. Mattson, S. Maudsley, and B. Martin, "A neural signaling triumvirate that influences ageing and agerelated disease: insulin/IGF-1, BDNF and serotonin," Ageing Research Reviews, vol. 3, no. 4, pp. 445-464, 2004.

[84] N. N. Johnson-Farley, T. Travkina, and D. S. Cowen, "Cumulative activation of Akt and consequent inhibition of glycogen synthase kinase- 3 by brain-derived neurotrophic factor and insulin-like growth factor-1 in cultured hippocampal neurons," Journal of Pharmacology and Experimental Therapeutics, vol. 316, no. 3, pp. 1062-1069, 2006.

[85] M. Hetman, K. Kanning, J. E. Cavanaugh, and Z. Xia, "Neuroprotection by brain-derived neurotrophic factor is mediated by extracellular signal-regulated kinase and phosphatidylinositol 3-kinase," Journal of Biological Chemistry, vol. 274, no. 32, pp. 22569-22580, 1999.

[86] J. D. Sweatt, "Mitogen-activated protein kinases in synaptic plasticity and memory," Current Opinion in Neurobiology, vol. 14, no. 3, pp. 311-317, 2004.

[87] J. J. Haddad, " $N$-methyl-D-aspartate (NMDA) and the regulation of mitogen-activated protein kinase (MAPK) signaling pathways: a revolving neurochemical axis for therapeutic intervention?" Progress in Neurobiology, vol. 77, no. 4, pp. 252-282, 2005.

[88] S. Subramaniam, N. Shahani, J. Strelau et al., "Insulin-like growth factor 1 inhibits extracellular signal-regulated kinase to promote neuronal survival via the phosphatidylinositol 3-kinase/protein kinase A/c-Raf pathway," Journal of Neuroscience, vol. 25, no. 11, pp. 2838-2852, 2005.

[89] J. David Sweatt, "The neuronal MAP kinase cascade: a biochemical signal integration system subserving synaptic plasticity and memory," Journal of Neurochemistry, vol. 76, no. 1, pp. 1-10, 2001.

[90] T. Purves, A. Middlemas, S. Agthong et al., "A role for mitogen-activated protein kinases in the etiology of diabetic neuropathy," FASEB Journal, vol. 15, no. 13, pp. 2508-2514, 2001.

[91] P. H. Groop, C. Forsblom, and M. C. Thomas, "Mechanisms of disease: pathway-selective insulin resistance and microvascular complications of diabetes," Nature Clinical Practice, vol. 1, no. 2, pp. 100-110, 2005.

[92] M. Maier, T. J. Seabrook, and C. A. Lemere, "Developing novel immunogens for an effective, safe Alzheimer's disease vaccine," Neurodegenerative Diseases, vol. 2, no. 5, pp. 267272, 2005.

[93] A. J. Barber, M. Nakamura, E. B. Wolpert et al., "Insulin rescues retinal neurons from apoptosis by a phosphatidylinositol 3-Kinase/Akt-mediated mechanism that reduces the activation of caspase-3," Journal of Biological Chemistry, vol. 276, no. 35, pp. 32814-32821, 2001.

[94] R. T. Watson and J. E. Pessin, "Intracellular organization of insulin signaling and GLUT4 translocation," Recent Progress in Hormone Research, vol. 56, pp. 175-193, 2001.

[95] S. Kang, J. Song, H. Kang, S. Kim, Y. Lee, and D. Park, "Insulin can block apoptosis by decreasing oxidative stress via phosphatidylinositol 3-kinase- and extracellular signalregulated protein kinase-dependent signaling pathways in 
HepG2 cells," European Journal of Endocrinology, vol. 148, no. 1, pp. 147-155, 2003.

[96] M. K. Barthwal, P. Sathyanarayana, C. N. Kundu et al., "Negative regulation of mixed lineage kinase 3 by protein kinase B/AKT leads to cell survival," Journal of Biological Chemistry, vol. 278, no. 6, pp. 3897-3902, 2003.

[97] Y. Okubo, V. A. Blakesley, B. Stannard, S. Gutkind, and D. L. Roith, "Insulin-like growth factor-I inhibits the stressactivated protein kinase/c-Jun N-terminal kinase," Journal of Biological Chemistry, vol. 273, no. 40, pp. 25961-25966, 1998.

[98] P. C. Geiger, D. C. Wright, D.-H. Han, and J. O. Holloszy, "Activation of p38 MAP kinase enhances sensitivity of muscle glucose transport to insulin," American Journal of Physiology, vol. 288, no. 4, pp. E782-E788, 2005.

[99] R. Somwar, S. Koterski, G. Sweeney et al., "A dominantnegative p38 MAPK mutant and novel selective inhibitors of p38 MAPK reduce insulin-stimulated glucose uptake in 3T3-L1 adipocytes without affecting GLUT4 translocation," Journal of Biological Chemistry, vol. 277, no. 52, pp. 5038650395, 2002.

[100] D. Konrad, R. Somwar, G. Sweeney et al., "The antihyperglycemic drug $\alpha$-lipoic acid stimulates glucose uptake via both GLUT4 translocation and GLUT4 activation: potential role of p38 mitogen-activated protein kinase in GLUT4 activation," Diabetes, vol. 50, no. 6, pp. 1464-1471, 2001.

[101] R. Somwar, M. Perreault, S. Kapur et al., "Activation of p38 mitogen-activated protein kinase $\alpha$ and $\beta$ by insulin and contraction in rat skeletal muscle: potential role in the stimulation of glucose transport," Diabetes, vol. 49, no. 11, pp. 1794-1800, 2000.

[102] G. Sweeney, R. Somwar, T. Ramlal, A. Volchuk, A. Ueyama, and A. Klip, "An inhibitor of p38 mitogen-activated protein kinase prevents insulin-stimulated glucose transport but not glucose transporter translocation in 3T3-L1 adipocytes and L6 myotubes," Journal of Biological Chemistry, vol. 274, no. 15, pp. 10071-10078, 1999.

[103] S. K. Kim, K. J. Woodcroft, and R. F. Novak, "Insulin and glucagon regulation of glutathione S-transferase expression in primary cultured rat hepatocytes," Journal of Pharmacology and Experimental Therapeutics, vol. 305, no. 1, pp. 353361, 2003.

[104] G. M. Leinninger, C. Backus, M. D. Uhler, S. I. Lentz, and E. L. Feldman, "Phosphatidylinositol 3-kinase and Akt effectors mediate insulin-like growth factor-I neuroprotection in dorsal root ganglia neurons," FASEB Journal, vol. 18, no. 13, pp. 1544-1546, 2004.

[105] L. Gasparini and H. Xu, "Potential roles of insulin and IGF-1 in Alzheimer's disease," Trends in Neurosciences, vol. 26, no. 8, pp. 404-406, 2003.

[106] M. S. Santos, E. M. Pereira, and A. P. Carvaho, "Stimulation of immunoreactive insulin release by glucose in rat brain synaptosomes," Neurochemical Research, vol. 24, no. 1, pp. 33-36, 1999.

[107] B. H. Shah and R. E. Hausman, "Effect of insulin on GABAergic development in the embryonic chick retina," Developmental Brain Research, vol. 72, no. 2, pp. 151-158, 1993.

[108] J. W. Yang, M. K. Raizada, and R. E. Fellows, "Effects of insulin on cultured rat brain cells: stimulation of ornithine decarboxylase activity," Journal of Neurochemistry, vol. 36, no. 3, pp. 1050-1057, 1981.

[109] D. Plitzko, S. Rumpel, and K. Gottmann, "Insulin promotes functional induction of silent synapses in differentiating rat neocortical neurons," European Journal of Neuroscience, vol. 14, no. 8, pp. 1412-1415, 2001.

[110] J. Kremerskothen, D. Wendholt, I. Teber, and A. Barnekow, "Insulin-induced expression of the activityregulated cytoskeleton-associated gene (ARC) in human neuroblastoma cells requires p21ras, mitogen-activated protein kinase/extracellular regulated kinase and src tyrosine kinases but is protein kinase C-independent," Neuroscience Letters, vol. 321, no. 3, pp. 153-156, 2002.

[111] C. Vilchis and R. Salceda, "Effect of diabetes on levels and uptake of putative amino acid neurotransmitters in rat retina and retinal pigment epithelium," Neurochemical Research, vol. 21, no. 10, pp. 1167-1171, 1996.

[112] A. Shuaib, M. S. Ijaz, T. Waqar et al., "Insulin elevates hippocampal GABA levels during ischemia. This is independent of its hypoglycemic effect," Neuroscience, vol. 67, no. 4, pp. 809-814, 1995.

[113] B. E. Levin, "Factors promoting and ameliorating the development of obesity," Physiology and Behavior, vol. 86, no. 5, pp. 633-639, 2005.

[114] J. L. Sievenpiper, A. L. Jenkins, D. L. Whitham, and V. Vuksan, "Insulin resistance: concepts, controversies, and the role of nutrition," Canadian Journal of Dietetic Practice and Research, vol. 63, no. 1, pp. 20-32, 2002.

[115] D. Porte, D. G. Baskin, and M. W. Schwartz, "Insulin signaling in the central nervous system: a critical role in metabolic homeostasis and disease from C. elegans to humans," Diabetes, vol. 54, no. 5, pp. 1264-1276, 2005.

[116] B. E. Levin, "Metabolic sensing neurons and the control of energy homeostasis," Physiology and Behavior, vol. 89, no. 4, pp. 486-489, 2006.

[117] G. J. Morton, D. E. Cummings, D. G. Baskin, G. S. Barsh, and M. W. Schwartz, "Central nervous system control of food intake and body weight," Nature, vol. 443, no. 7109, pp. 289295, 2006.

[118] J. Girard, "The inhibitory effects of insulin on hepatic glucose production are both direct and indirect," Diabetes, vol. 55, no. 2, pp. S65-S69, 2006.

[119] S. Obici, Z. Feng, G. Karkanias, D. G. Baskin, and L. Rossetti, "Decreasing hypothalamic insulin receptors causes hyperphagia and insulin resistance in rats," Nature Neuroscience, vol. 5, no. 6, pp. 566-572, 2002.

[120] A. L. McCall, "Cerebral glucose metabolism in diabetes mellitus," European Journal of Pharmacology, vol. 490, no. 13, pp. 147-158, 2004.

[121] K. A. Heidenreich and D. Brandenburg, "Oligosaccharide heterogeneity of insulin receptors. Comparison of N-linked glycosylation of insulin receptors in adipocytes and brain," Endocrinology, vol. 118, no. 5, pp. 1835-1842, 1986.

[122] D. W. Clarke, F. T. Boyd, M. S. Kappy, and K. Raizada, "Insulin binds to specific receptors and stimulates 2-deoxyD-glucose uptake in cultured glial cells from rat brain," Journal of Biological Chemistry, vol. 259, no. 19, pp. 1167211675, 1984.

[123] S. Hoyer and L. Frölich, "Brain function and insulin signal transduction in sporadic Alzheimer's disease," in Research Progress in Alzheimer's Disease and Dementia, M. Sich, Ed., pp. 23-46, Nova Science, New York, NY, USA, 2006.

[124] C. R. Park, "Cognitive effects of insulin in the central nervous system," Neuroscience and Biobehavioral Reviews, vol. 25, no. 4, pp. 311-323, 2001.

[125] S. J. Vannucci, E. M. Koehler-Stec, K. Li, T. H. Reynolds, R. Clark, and I. A. Simpson, "GLUT4 glucose transporter 
expression in rodent brain: effect of diabetes," Brain Research, vol. 797, no. 1, pp. 1-11, 1998.

[126] S. Craft and G. S. Watson, "Insulin and neurodegenerative disease: shared and specific mechanisms," Lancet Neurology, vol. 3, no. 3, pp. 169-178, 2004.

[127] E. M. Bingham, D. Hopkins, D. Smith et al., "The role of insulin in human brain glucose metabolism: an 18fluorodeoxyglucose positron emission tomography study," Diabetes, vol. 51, no. 12, pp. 3384-3390, 2002.

[128] A. Ghosh, Y. C. Yuk, B. C. Mansfield, and J. Y. Chou, "Brain contains a functional glucose-6-phosphatase complex capable of endogenous glucose production," Journal of Biological Chemistry, vol. 280, no. 12, pp. 11114-11119, 2005.

[129] J. W. Russell, D. Golovoy, A. M. Vincent et al., "High glucoseinduced oxidative stress and mitochondrial dysfunction in nuerons," FASEB Journal, vol. 16, no. 13, pp. 1738-1748, 2002.

[130] X. Wu, C. E. N. Reiter, D. A. Antonetti, S. R. Kimball, L. S. Jefferson, and T. W. Gardner, "Insulin Promotes Rat Retinal Neuronal Cell Survival in a p70S6K-dependent Manner," Journal of Biological Chemistry, vol. 279, no. 10, pp. 91679175, 2004.

[131] J. R. Koo and N. D. Vaziri, "Effects of diabetes, insulin and antioxidants on No synthase abundance and No interaction with reactive oxygen species," Kidney International, vol. 63, no. 1, pp. 195-201, 2003.

[132] A. I. Duarte, T. Proença, C. R. Oliveira, M. S. Santos, and A. C. Rego, "Insulin restores metabolic function in cultured cortical neurons subjected to oxidative stress," Diabetes, vol. 55, no. 10, pp. 2863-2870, 2006.

[133] U. Stockhorst, D. De Fries, H.-J. Steingrueber, and W. A. Scherbaum, "Insulin and the CNS: effects on food intake, memory, and endocrine parameters and the role of intranasal insulin administration in humans," Physiology and Behavior, vol. 83, no. 1, pp. 47-54, 2004.

[134] E. R. Seaquist, G. S. Damberg, I. Tkac, and R. Gruetter, “The effect of insulin on in vivo cerebral glucose concentrations and rates of glucose transport/metabolism in humans," Diabetes, vol. 50, no. 10, pp. 2203-2209, 2001.

[135] S. G. Hasselbalch, G. M. Knudsen, C. Videbaek et al., "No effect of insulin on glucose blood-brain barrier transport and cerebral metabolism in humans," Diabetes, vol. 48, no. 10, pp. 1915-1921, 1999.

[136] B. J. Dickson, "Wiring the brain with insulin," Science, vol. 300, no. 5618, pp. 440-441, 2003.

[137] J. Song, L. Wu, Z. Chen, R. A. Kohanski, and L. Pick, "Axons guided by insulin receptor in Drosophila visual system," Science, vol. 300, no. 5618, pp. 502-505, 2003.

[138] K. Sugimoto, M. Baba, T. Suda, M. Yasujima, and S. Yagihashi, "Peripheral neuropathy and microangiopathy in rats with insulinoma: association with chronic hyperinsulinemia," Diabetes/Metabolism Research and Reviews, vol. 19, no. 5, pp. 392-400, 2003.

[139] I. Torres-Aleman, "Insulin-like growth factors as mediators of functional plasticity in the adult brain," Hormone and Metabolic Research, vol. 31, no. 2-3, pp. 114-119, 1999.

[140] E. Recio-Pinto, M. M. Rechler, and D. N. Ishii, "Effects of insulin, insulin-like growth factor-II, and nerve growth factor on neurite formation and survival cultured sympathetic and sensory neurons," Journal of Neuroscience, vol. 6, no. 5, pp. 1211-1219, 1986.

[141] H. Dudek, S. R. Datta, T. F. Franke et al., "Regulation of neuronal survival by the serine-threonine protein kinase Akt," Science, vol. 275, no. 5300, pp. 661-665, 1997.
[142] M. Tanaka, M. Sawada, S. Yoshida, F. Hanaoka, and T. Marunouchi, "Insulin prevents apoptosis of external granular layer neurons in rat cerebellar slice cultures," Neuroscience Letters, vol. 199, no. 1, pp. 37-40, 1995.

[143] T. Takadera, N. Sakura, T. Mohri, and T. Hashimoto, "Toxic effect of a beta-amyloid peptide (beta 22-35) on the hippocampa 1 neuron and its prevention," Neuroscience Letters, vol. 14, pp. 41-44, 1993.

[144] C. Benedict, M. Hallschmid, A. Hatke et al., "Intranasal insulin improves memory in humans," Psychoneuroendocrinology, vol. 29, no. 10, pp. 1326-1334, 2004.

[145] W. Kern, A. Peters, B. Fruehwald-Schultes, E. Deininger, J. Born, and H. L. Fehm, "Improving influence of insulin on cognitive functions in humans," Neuroendocrinology, vol. 74, no. 4, pp. 270-280, 2001.

[146] F. T. Boyd, D. W. Clarke, and M. K. Raizada, "Insulin inhibits specific norepinephrine uptake in neuronal cultures from rat brain,” Brain Research, vol. 398, no. 1, pp. 1-5, 1986.

[147] M. L. Barbaccia, D. M. Chuang, and E. Costa, "Is insulin a neuromodulator?" Advances in Biochemical Psychopharmacology, vol. 33, pp. 511-518, 1982.

[148] A. Sauter, M. Goldstein, J. Engel, and K. Ueta, "Effect of insulin on central catecholamines," Brain Research, vol. 260, no. 2, pp. 330-333, 1983.

[149] M. K. Raizada, J. Shemer, J. H. Judkins, D. W. Clarke, B. A. Masters, and D. LeRoith, "Insulin receptors in the brain: structural and physiological characterization," Neurochemical Research, vol. 13, no. 4, pp. 297-303, 1988.

[150] B. A. Masters, J. Shemer, J. H. Judkins, D. W. Clarke, D. Le Roith, and M. K. Raizada, "Insulin receptors and insulin action in dissociated brain cells," Brain Research, vol. 417, no. 2, pp. 247-256, 1987.

[151] E. M. Richards, M. K. Raizada, and C. Summers, "Insulin downregulates alpha-2 adrenergic receptors in cultured glial cells," in Insulin, Insulin-Like Growth Factors and Their Receptors in the Central Nervous System, M. K. Raizada, M. I. Phillips, and D. Le Roith, Eds., p. 209, 1987.

[152] F. T. Boyd, D. W. Clarke, T. F. Muther, and M. K. Raizada, "Insulin receptors and insulin modulation of norepinephrine uptake in neuronal cultures from rat brain," Journal of Biological Chemistry, vol. 260, no. 29, pp. 15880-15884, 1985.

[153] V. A. Skeberdis, J. Y. Lan, X. Zheng, R. S. Zukin, and M. V. L. Bennett, "Insulin promotes rapid delivery of N-methylD-aspartate receptors to the cell surface by exocytosis," Proceedings of the National Academy of Sciences of the United States of America, vol. 98, no. 6, pp. 3561-3566, 2001.

[154] L. P. Van Der Heide, A. Kamal, A. Artola, W. H. Gispen, and G. M. J. Ramakers, "Insulin modulates hippocampal activity-dependent synaptic plasticity in a N-methylD-aspartate receptor and phosphatidyl-inositol-3-kinasedependent manner," Journal of Neurochemistry, vol. 94, no. 4, pp. 1158-1166, 2005.

[155] A. I. Duarte, M. S. Santos, R. Seiça, and C. R. Oliveira, "Oxidative stress affects synaptosomal $\gamma$-aminobutyric acid and glutamate transport in diabetic rats: the role of insulin," Diabetes, vol. 53, no. 8, pp. 2110-2116, 2004.

[156] A. I. Duarte, M. S. Santos, R. Seiça, and C. R. De Oliveira, "Insulin affects synaptosomal GABA and glutamate transport under oxidative stress conditions," Brain Research, vol. 977, no. 1, pp. 23-30, 2003.

[157] A. I. Duarte, M. S. Santos, C. R. Oliveira, and A. C. Rego, "Insulin neuroprotection against oxidative stress in cortical neurons-involvement of uric acid and glutathione 
antioxidant defenses," Free Radical Biology and Medicine, vol. 39, no. 7, pp. 876-889, 2005.

[158] W. Hamabe, R. Fujita, and H. Ueda, "Neuronal necrosis inhibition by insulin through protein kinase C activation," Journal of Pharmacology and Experimental Therapeutics, vol. 307, no. 1, pp. 205-212, 2003.

[159] F. Hong, S. J. Kwon, B. S. Jhun et al., "Insulin-like growth factor-1 protects $\mathrm{H} 9 \mathrm{c} 2$ cardiac myoblasts from oxidative stress-induced apoptosis via phosphatidylinositol 3-kinase and extracellular signal-regulated kinase pathways," Life Sciences, vol. 68, no. 10, pp. 1095-1105, 2001.

[160] B. R. Ryu, H. W. Ko, I. Jou, J. S. Noh, and B. J. Gwag, "Phosphatidylinositol 3-kinase-mediated regulation of neuronal apoptosis and necrosis by insulin and IGF-I," Journal of Neurobiology, vol. 39, no. 4, pp. 536-546, 1999.

[161] B. J. Gwag, J. Y. Koh, J. A. Demaro, H. S. Ying, M. Jacquin, and D. W. Choi, "Slowly triggered excitotoxicity occurs by necrosis in cortical cultures," Neuroscience, vol. 77, no. 2, pp. 393-401, 1997.

[162] S. R. D’Mello, C. Galli, T. Ciotti, and P. Calissano, "Induction of apoptosis in cerebellar granule neurons by low potassium: inhibition of death by insulin-like growth factor I and cAMP," Proceedings of the National Academy of Sciences of the United States of America, vol. 90, no. 23, pp. 10989-10993, 1993.

[163] G. Kyriaki, "Brain insulin: regulation, mechanisms of action and functions," Cellular and Molecular Neurobiology, vol. 23, no. 1, pp. 1-25, 2003.

[164] G. S. Watson and S. Craft, "The role of insulin resistance in the pathogenesis of Alzheimer's disease: implications for treatment," CNS Drugs, vol. 17, no. 1, pp. 27-45, 2003.

[165] P. C. Chin, N. Majdzadeh, and S. R. D’Mello, “Inhibition of GSK3 $\beta$ is a common event in neuroprotection by different survival factors," Molecular Brain Research, vol. 137, no. 1-2, pp. 193-201, 2005.

[166] S. J. Kim and Y. Han, "Insulin inhibits AMPA-induced neuronal damage via stimulation of protein kinase B (Akt)," Journal of Neural Transmission, vol. 112, no. 2, pp. 179-191, 2005.

[167] M. Schubert, D. Gautam, D. Surjo et al., "Role for neuronal insulin resistance in neurodegenerative diseases," Proceedings of the National Academy of Sciences of the United States of America, vol. 101, no. 9, pp. 3100-3105, 2004.

[168] K. M. Noh, J. C. Lee, Y. H. Ahn, S. H. Hong, and J. Y. Koh, "Insulin-induced oxidative neuronal injury in cortical culture: mediation by induced N-methyl-D-aspartate receptors," IUBMB Life, vol. 48, no. 3, pp. 263-269, 1999.

[169] World Health Organization, "Diabetes facts," Fact sheet no. 312, 2011, http://www.who.int/mediacentre/factsheets/ fs $312 /$ en/.

[170] T. Tuomi, "Type 1 and type 2 diabetes: what do they have in common?" Diabetes, vol. 54, supplement 2, pp. S40-S45, 2005.

[171] A. M. Vincent, L. L. McLean, C. Backus, and E. L. Feldman, "Short-term hyperglycemia produces oxidative damage and apoptosis in neurons," FASEB Journal, vol. 19, no. 6, pp. 638640, 2005.

[172] G. J. Biessels, L. P. Van der Heide, A. Kamal, R. L. A. W. Bleys, and W. H. Gispen, "Ageing and diabetes: implications for brain function," European Journal of Pharmacology, vol. 441, no. 1-2, pp. 1-14, 2002.

[173] S. Craft, "Insulin resistance syndrome and Alzheimer's disease: age- and obesity-related effects on memory, amyloid, and inflammation," Neurobiology of Aging, vol. 26, supplement, pp. S65-S69, 2005.
[174] M. Ristow, "Neurodegenetive disorders associated with diabetes mellitus," Journal of Molecular Medicine, vol. 82, no. 8, pp. 510-529, 2004.

[175] G. S. Watson and S. Craft, "Modulation of memory by insulin and glucose: neuropsychological observations in Alzheimer's disease," European Journal of Pharmacology, vol. 490, no. 1-3, pp. 97-113, 2004.

[176] G. G. Piroli, C. A. Grillo, M. J. Charron, B. S. McEwen, and L. P. Reagan, "Biphasic effects of stress upon GLUT8 glucose transporter expression and trafficking in the diabetic rat hippocampus," Brain Research, vol. 1006, no. 1, pp. 28-35, 2004.

[177] M. S. Santos, A. I. Duarte, M. J. Matos, T. Proença, R. Seiça, and C. R. Oliveira, "Synaptosomes isolated from GotoKakizaki diabetic rat brain exhibit increased resistance to oxidative stress: role of vitamin E," Life Sciences, vol. 67, no. 25, pp. 3061-3073, 2000.

[178] P. I. Moreira, M. S. Santos, A. M. Moreno, R. Seiça, and C. R. Oliveira, "Increased vulnerability of brain mitochondria in diabetic (goto-kakizaki) rats with aging and amyloid- $\beta$ exposure," Diabetes, vol. 52, no. 6, pp. 1449-1456, 2003.

[179] P. I. Moreira, M. S. Santos, C. Sena, E. Nunes, R. Seiça, and C. R. Oliveira, "CoQ10 therapy attenuates amyloid $\beta$-peptide toxicity in brain mitochondria isolated from aged diabetic rats," Experimental Neurology, vol. 196, no. 1, pp. 112-119, 2005.

[180] P. I. Moreira, M. S. Santos, C. Sena, R. Seiça, and C. R. Oliveira, "Insulin protects against amyloid $\beta$-peptide toxicity in brain mitochondria of diabetic rats," Neurobiology of Disease, vol. 18, no. 3, pp. 628-637, 2005.

[181] S. Correia, C. Carvalho, M. S. Santos et al., "Metformin protects the brain against the oxidative imbalance promoted by type 2 diabetes," Medicinal Chemistry, vol. 4, no. 4, pp. 358-364, 2008.

[182] R. Mastrocola, F. Restivo, I. Vercellinatto et al., "Oxidative and nitrosative stress in brain mitochondria of diabetic rats," Journal of Endocrinology, vol. 187, no. 1, pp. 37-44, 2005.

[183] Z. G. Li, W. Zhang, and A. A. F. Sima, "The role of impaired insulin/IGF action in primary diabetic encephalopathy," Brain Research, vol. 1037, no. 1-2, pp. 12-24, 2005.

[184] S. Correia, C. Carvalho, M. S. Santos, R. Seiça, C. R. Oliveira, and P. I. Moreira, "Mechanisms of action of metformin in type 2 diabetes and associated complications: an overview," Mini reviews in Medicinal Chemistry, vol. 8, no. 13, pp. 13431354, 2008.

[185] I. G. Obrosova, V. R. Drel, P. Pacher et al., "Oxidativenitrosative stress and poly(ADP-ribose) polymerase (PARP) activation in experimental diabetic neuropathy: the relation is revisited," Diabetes, vol. 54, no. 12, pp. 3435-3441, 2005.

[186] L. L. Guyot, F. G. Diaz, M. H. O’Regan, D. Song, and J. W. Phillis, "The effect of topical insulin on the release of excitotoxic and other amino acids from the rat cerebral cortex during streptozotocin-induced hyperglycemic ischemia," Brain Research, vol. 872, no. 1-2, pp. 29-36, 2000.

[187] L. L. Guyot, F. G. Diaz, M. H. O’Regan, D. Song, and J. W. Phillis, "Topical insulin and accumulation of excitotoxic and other amino acids in ischemic rat cerebral cortex," Experimental Biology and Medicine, vol. 224, no. 1, pp. 2831,2000 .

[188] J. W. Phillis, D. Song, and M. H. O’Regan, "Effect of hyperglycemia on extracellular levels of amino acids and free fatty acids in the ischemic/reperfused rat cerebral cortex," Brain Research, vol. 837, no. 1-2, pp. 177-183, 1999. 
[189] S. Cardoso, C. Carvalho, R. Santos et al., "Impact of STZinduced hyperglycemia and insulin-induced hypoglycemia in plasma amino acids and cortical synaptosomal neurotransmitters," Synapse, vol. 65, no. 6, pp. 457-466, 2011.

[190] W. A. Hsueh, L. M. Moore, and M. Bryer-Ash, "Pathophysiology of type 2 diabetes: a quartet of abnormalities," in Contemporary Diagnosis and Management of Type 2 Diabetes, W. A. Hsueh, L. M. Moore, and M. Bryer-Ash, Eds., pp. 5-19, Handbooks in Health Care, Newtown, Pa, USA, 2nd edition, 2004.

[191] J. Buse, "Combining insulin and oral agents," American Journal of Medicine, vol. 108, no. supplement 6, pp. 23-32, 2000.

[192] R. C. Turner, C. A. Cull, V. Frighi, and R. R. Holman, "Glycemic control with diet, sulfonylurea, metformin, or insulin in patients with type 2 diabetes mellitus. Progressive requirement for multiple therapies (UKPDS 49)," Journal of the American Medical Association, vol. 281, no. 21, pp. 20052012, 1999.

[193] P. Singh, A. Jain, and G. Kaur, "Impact of hypoglycemia and diabetes on CNS: correlation of mitochondrial oxidative stress with DNA damage," Molecular and Cellular Biochemistry, vol. 260, no. 1, pp. 153-159, 2004.

[194] P. I. Moreira, A. P. Rolo, C. Sena, R. Seiça, C. R. Oliveira, and M. S. Santos, "Insulin attenuates diabetes-related mitochondrial alterations: a comparative study," Medicinal Chemistry, vol. 2, no. 3, pp. 299-308, 2006.

[195] G. J. Biessels and W. H. Gispen, "The impact of diabetes on cognition: what can be learned from rodent models?" Neurobiology of Aging, vol. 26, supplement, pp. S36-S41, 2005.

[196] M. Brownlee, "Biochemistry and molecular cell biology of diabetic complications," Nature, vol. 414, no. 6865, pp. 813$820,2001$.

[197] N. N. Rizk, J. Rafols, and J. C. Dunbar, "Cerebral ischemia induced apoptosis and necrosis in normal and diabetic rats," Brain Research, vol. 1053, no. 1-2, pp. 1-9, 2005.

[198] Y. Soeda, H. Tsuneki, H. Muranaka et al., "The inositol phosphatase SHIP2 negatively regulates insulin/IGF-I actions implicated in neuroprotection and memory function in mouse brain," Molecular Endocrinology, vol. 24, no. 10, pp. 1965-1977, 2010.

[199] W. H. Gispen and G. J. Biessels, "Cognition and synaptic plasticity in diabetes mellitus," Trends in Neurosciences, vol. 23 , no. 11 , pp. 542-549, 2000.

[200] L. Gasparini, W. J. Netzer, P. Greengard, and H. Xu, "Does insulin dysfunction play a role in Alzheimer's disease?" Trends in Pharmacological Sciences, vol. 23, no. 6, pp. 288293, 2002.

[201] V. Brussee, F. A. Cunningham, and D. W. Zochodne, "Direct insulin signalling of neurons reverses diabetic neuropathy," Diabetes, vol. 53, no. 7, pp. 1824-1830, 2004.

[202] J. Vijg and Y. Suh, "Genetics of longevity and aging," Annual Review of Medicine, vol. 56, pp. 193-212, 2005.

[203] R. A. Miller, "Cell stress and aging: new emphasis on multiplex resistance mechanisms," Journals of Gerontology A, vol. 64, no. 2, pp. 179-182, 2009.

[204] D. Harman, "Free radical theory of aging: effect of free radical reaction inhibitors on the mortality rate of male LAF mice," Journals of Gerontology, vol. 23, no. 4, pp. 476-482, 1968.

[205] G. J. Brewer, "Epigenetic oxidative redox shift (EORS) theory of aging unifies the free radical and insulin signaling theories," Experimental Gerontology, vol. 45, no. 3, pp. 173$179,2010$.
[206] E. R. Miller, R. Pastor-Barriuso, D. Dalal, R. A. Riemersma, L. J. Appel, and E. Guallar, "Meta-analysis: high-dosage vitamin E supplementation may increase all-cause mortality," Annals of Internal Medicine, vol. 142, no. 1, pp. 37-46, 2005.

[207] G. Bjelakovic, D. Nikolova, L. L. Gluud, R. G. Simonetti, and C. Gluud, "Mortality in randomized trials of antioxidant supplements for primary and secondary prevention: systematic review and meta-analysis," Journal of the American Medical Association, vol. 297, no. 8, pp. 842-857, 2007.

[208] V. I. Pérez, H. Van Remmen, A. Bokov, C. J. Epstein, J. Vijg, and A. Richardson, "The overexpression of major antioxidant enzymes does not extend the lifespan of mice," Aging Cell, vol. 8, no. 1, pp. 73-75, 2009.

[209] A. Mitsui, J. Hamuro, H. Nakamura et al., "Overexpression of human thioredoxin in transgenic mice controls oxidative stress and life span," Antioxidants and Redox Signaling, vol. 4, no. 4, pp. 693-696, 2002.

[210] S. E. Schriner, N. J. Linford, G. M. Martin et al., "Medecine: extension of murine life span by overexpression of catalase targeted to mitochondria," Science, vol. 308, no. 5730, pp. 1909-1911, 2005.

[211] R. Weindruch, T. Kayo, C. K. Lee, and T. A. Prolla, "Microarray profiling of gene expression in aging and its alteration by caloric restriction in mice," Journal of Nutrition, vol. 131, no. 3, pp. 918S-923S, 2001.

[212] C. S. Carter, M. M. Ramsey, and W. E. Sonntag, "A critical analysis of the role of growth hormone and IGF-1 in aging and lifespan," Trends in Genetics, vol. 18, no. 6, pp. 295-301, 2002.

[213] L. K. Heilbronn, L. De Jonge, M. I. Frisard et al., "Effect of 6-month calorie restriction on biomarkers of longevity, metabolic adaptation, and oxidative stress in overweight individuals: a randomized controlled trial," Journal of the American Medical Association, vol. 295, no. 13, pp. 15391548, 2006.

[214] K. A. Al-Regaiey, M. M. Masternak, M. S. Bonkowski, J. A. Panici, J. J. Kopchick, and A. Bartke, "Effects of caloric restriction and growth hormone resistance on insulin-related intermediates in the skeletal muscle," Journals of Gerontology A, vol. 62, no. 1, pp. 18-26, 2007.

[215] M. M. Masternak, K. A. Al-Regaiey, M. M. D. R. Lim et al., "Effects of caloric restriction on insulin pathway gene expression in the skeletal muscle and liver of normal and long-lived GHR-KO mice," Experimental Gerontology, vol. 40, no. 8-9, pp. 679-684, 2005.

[216] R. Westbrook, M. S. Bonkowski, A. D. Strader, and A. Bartke, "Alterations in oxygen consumption, respiratory quotient, and heat production in long-lived GHRKO and Ames dwarf mice, and short-lived bGH transgenic mice," Journals of Gerontology A, vol. 64, no. 4, pp. 443-451, 2009.

[217] T. Kimura, J. Takamatsu, K. Ikeda, A. Kondo, T. Miyakawa, and S. Horiuchi, "Accumulation of advanced glycation end products of the Maillard reaction with age in human hippocampal neurons," Neuroscience Letters, vol. 208, no. 1, pp. 53-56, 1996.

[218] L. Plum, M. Schubert, and J. C. Brüning, "The role of insulin receptor signaling in the brain," Trends in Endocrinology and Metabolism, vol. 16, no. 2, pp. 59-65, 2005.

[219] L. Frölich, D. Blum-Degen, H.-G. Bernstein et al., "Brain insulin and insulin receptors in aging and sporadic Alzheimer's disease," Journal of Neural Transmission, vol. 105, no. 4-5, pp. 423-438, 1998. 
[220] N. Potau, M. A. Escofet, and M. C. Martinez, "Ontogenesis of insulin receptors in human cerebral cortex," Journal of Endocrinological Investigation, vol. 14, no. 1, pp. 53-58, 1991.

[221] L. Pawlikowska, D. Hu, S. Huntsman et al., "Association of common genetic variation in the insulin/IGF1 signaling pathway with human longevity," Aging Cell, vol. 8, no. 4, pp. 460-472, 2009.

[222] A. Taguchi, L. M. Wartschow, and M. F. White, "Brain IRS2 signaling coordinates life span and nutrient homeostasis," Science, vol. 317, no. 5836, pp. 369-372, 2007.

[223] H. Kurosu, M. Yamamoto, J. D. Clark et al., "Physiology: suppression of aging in mice by the hormone Klotho," Science, vol. 309, no. 5742, pp. 1829-1833, 2005.

[224] D. Van Heemst, M. Beekman, S. P. Mooijaart et al., "Reduced insulin/IGF-1 signalling and human longevity," Aging Cell, vol. 4, no. 2, pp. 79-85, 2005.

[225] M. Blüher, B. B. Kahn, and C. R. Kahn, "Extended longevity in mice lacking the insulin receptor in adipose tissue," Science, vol. 299, no. 5606, pp. 572-574, 2003.

[226] A. Bartke, "Impact of reduced insulin-like growth factor1/insulin signaling on aging in mammals: novel findings," Aging Cell, vol. 7, no. 3, pp. 285-290, 2008.

[227] J. H. Hahm, S. Kim, and Y. K. Paik, "Endogenous cGMP regulates adult longevity via the insulin signaling pathway in Caenorhabditis elegans," Aging Cell, vol. 8, no. 4, pp. 473483, 2009.

[228] M. D. Nielsen, X. Luo, B. Biteau, K. Syverson, and H. Jasper, "14-3-3 $\varepsilon$ antagonizes FoxO to control growth, apoptosis and longevity in Drosophila," Aging Cell, vol. 7, no. 5, pp. 688699, 2008.

[229] L. Zhou, H. Chen, P. Xu et al., "Action of insulin receptor substrate-3 (IRS-3) and IRS-4 to stimulate translocation of GLUT4 in rat adipose cells," Molecular Endocrinology, vol. 13, no. 3, pp. 505-514, 1999.

[230] L. Frittitta, R. Vigneri, M. R. Stampfer, and I. D. Goldfine, "Insulin receptor overexpression in 184B5 human mammary epithelial cells induces a ligand-dependent transformed phenotype," Journal of Cellular Biochemistry, vol. 57, no. 4, pp. 666-669, 1995.

[231] M. Barbieri, M. Bonafè, C. Franceschi, and G. Paolisso, "Insulin/IGF-I-signaling pathway: an evolutionarily conserved mechanism of longevity from yeast to humans," American Journal of Physiology, vol. 285, no. 5, pp. E1064E1071, 2003.

[232] N. A. Bishop, T. Lu, and B. A. Yankner, "Neural mechanisms of ageing and cognitive decline," Nature, vol. 464, no. 7288, pp. 529-535, 2010.

[233] J. M. Copeland, J. Cho, T. Lo et al., "Extension of Drosophila life span by RNAi of the mitochondrial respiratory chain," Current Biology, vol. 19, no. 19, pp. 1591-1598, 2009.

[234] C. Dell'Agnello, S. Leo, A. Agostino et al., "Increased longevity and refractoriness to $\mathrm{Ca}^{2+}$-dependent neurodegeneration in Surf1 knockout mice," Human Molecular Genetics, vol. 16, no. 4, pp. 431-444, 2007.

[235] R. Brookmeyer, E. Johnson, K. Ziegler-Graham, and H. M. Arrighi, "Forecasting the global burden of Alzheimer's disease," Alzheimer's and Dementia, vol. 3, no. 3, pp. 186-191, 2007.

[236] D. J. Selkoe, "Translating cell biology into therapeutic advances in Alzheimer's disease," Nature, vol. 399, pp. A23A31, 1999.

[237] K. Uemura, A. Kuzuya, and S. Shimohama, "Protein trafficking and Alzheimer's disease," Current Alzheimer Research, vol. 1, no. 1, pp. 1-10, 2004.
[238] E. Carro and I. Torres-Aleman, "The role of insulin and insulin-like growth factor I in the molecular and cellular mechanisms underlying the pathology of Alzheimer's disease," European Journal of Pharmacology, vol. 490, no. 1-3, pp. 127-133, 2004.

[239] A. Rocchi, S. Pellegrini, G. Siciliano, and L. Murri, "Causative and susceptibility genes for Alzheimer's disease: a review," Brain Research Bulletin, vol. 61, no. 1, pp. 1-24, 2003.

[240] E. Grünblatt, E. Koutsilieri, S. Hoyer, and P. Riederer, "Gene expression alterations in brain areas of intracerebroventricular streptozotocin treated rat," Journal of Alzheimer's Disease, vol. 9, no. 3, pp. 261-271, 2006.

[241] B. H. Anderton, "Ageing of the brain," Mechanisms of Ageing and Development, vol. 123, no. 7, pp. 811-817, 2002.

[242] A. Eckert, U. Keil, C. A. Marques et al., "Mitochondrial dysfunction, apoptotic cell death, and Alzheimer's disease," Biochemical Pharmacology, vol. 66, no. 8, pp. 1627-1634, 2003.

[243] G. Perry, M. A. Taddeo, R. B. Petersen et al., "Adventiouslybound redox active iron and copper are at the center of oxidative damage in Alzheimer disease," BioMetals, vol. 16, no. 1, pp. 77-81, 2003.

[244] D. A. Butterfield and D. Boyd-Kimball, "The critical role of methionine 35 in Alzheimer's amyloid $\beta$-peptide (1-42)induced oxidative stress and neurotoxicity," Biochimica et Biophysica Acta, vol. 1703, no. 2, pp. 149-156, 2005.

[245] J. K. Andersen, "Oxidative stress in neurodegeneration: cause or consequence?" Nature Medicine, vol. 10, supplement, pp. S18-S25, 2004.

[246] P. Rinaldi, M. C. Polidori, A. Metastasio et al., "Plasma antioxidants are similarly depleted in mild cognitive impairment and in Alzheimer's disease," Neurobiology of Aging, vol. 24, no. 7, pp. 915-919, 2003.

[247] Y. Gilgun-Sherki, E. Melamed, and D. Offen, "Oxidative stress induced-neurodegenerative diseases: the need for antioxidants that penetrate the blood brain barrier," Neuropharmacology, vol. 40, no. 8, pp. 959-975, 2001.

[248] M. A. Smith, L. M. Sayre, V. E. Anderson et al., "Cytochemical demonstration of oxidative damage in Alzheimer disease by immunochemical enhancement of the carbonyl reaction with 2,4-dinitrophenylhydrazine," Journal of Histochemistry and Cytochemistry, vol. 46, no. 6, pp. 731-735, 1998.

[249] P. P. Zandi, J. C. Anthony, A. S. Khachaturian et al., "Reduced risk of Alzheimer disease in users of antioxidant vitamin supplements: the Cache County study," Archives of Neurology, vol. 61, no. 1, pp. 82-88, 2004.

[250] E. T. Klatte, D. W. Scharre, H. N. Nagaraja, R. A. Davis, and D. Q. Beversdorf, "Combination therapy of donepezil and vitamin E in Alzheimer disease," Alzheimer Disease and Associated Disorders, vol. 17, no. 2, pp. 113-116, 2003.

[251] R. B. Maccioni, J. P. Muñoz, and L. Barbeito, “The molecular bases of Alzheimer's disease and other neurodegenerative disorders," Archives of Medical Research, vol. 32, no. 5, pp. 367-381, 2001.

[252] B. Moosmann and C. Behl, "Antioxidants as treatment for neurodegenerative disorders," Expert Opinion on Investigational Drugs, vol. 11, no. 10, pp. 1407-1435, 2002.

[253] J. A. Luchsinger, M. X. Tang, S. Shea, and R. Mayeux, "Antioxidant vitamin intake and risk of Alzheimer disease," Archives of Neurology, vol. 60, no. 2, pp. 203-208, 2003.

[254] D. J. Piñero, J. Hu, and J. R. Connor, "Alterations in the interaction between iron regulatory proteins and their iron responsive element in normal and Alzheimer's diseased 
brains," Cellular and Molecular Biology, vol. 46, no. 4, pp. 761-776, 2000.

[255] J. P. Blass, R. K. F. Sheu, and G. E. Gibson, "Inherent abnormalities in energy metabolism in Alzheimer disease: interaction with cerebrovascular compromise," Annals of the New York Academy of Sciences, vol. 903, pp. 204-221, 2000.

[256] S. Hoyer, "Is sporadic Alzheimer disease the brain type of non-insulin dependent diabetes mellitus? A challenging hypothesis," Journal of Neural Transmission, vol. 105, no. 45, pp. 415-422, 1998.

[257] H. Fukuyama, M. Ogawa, H. Yamauchi et al., "Altered cerebral energy metabolism in Alzheimer's disease: a PET study," Journal of Nuclear Medicine, vol. 35, no. 1, pp. 1-6, 1994.

[258] G. W. Small, S. Komo, A. La Rue et al., "Early detection of Alzheimer's disease by combining apolipoprotein E and neuroimaging," Annals of the New York Academy of Sciences, vol. 802, pp. 70-78, 1996.

[259] S. Hoyer, "Glucose metabolism and insulin receptor signal transduction in Alzheimer disease," European Journal of Pharmacology, vol. 490, no. 1-3, pp. 115-125, 2004.

[260] Y. Liu, F. Liu, K. Iqbal, I. Grundke-Iqbal, and C. X. Gong, "Decreased glucose transporters correlate to abnormal hyperphosphorylation of tau in Alzheimer disease," FEBS Letters, vol. 582, no. 2, pp. 359-364, 2008.

[261] P. I. Moreira, M. S. Santos, and C. R. Oliveira, "Alzheimer's disease: a lesson from mitochondrial dysfunction," Antioxidants and Redox Signaling, vol. 9, no. 10, pp. 1621-1630, 2007.

[262] G. E. Gibson, L. C.H. Park, K.-F. R. Sheu, J. P. Blass, and N. Y. Calingasan, "The $\alpha$-ketoglutarate dehydrogenase complex in neurodegeneration," Neurochemistry International, vol. 36, no. 2, pp. 97-112, 2000.

[263] S. J. Kish, "Brain energy metabolizing enzymes in Alzheimer's disease: $\alpha$-ketoglutarate dehydrogenase complex and cytochrome oxidase," Annals of the New York Academy of Sciences, vol. 826, pp. 218-228, 1997.

[264] S. Sorbi, E. D. Bird, and J. P. Blass, "Decreased pyruvate dehydrogenase complex activity in Huntington and Alzheimer brain," Annals of Neurology, vol. 13, no. 1, pp. 72-78, 1983.

[265] P. Bubber, V. Haroutunian, G. Fisch, J. P. Blass, and G. E. Gibson, "Mitochondrial abnormalities in Alzheimer brain: mechanistic implications," Annals of Neurology, vol. 57, no. 5, pp. 695-703, 2005.

[266] S. M. Cardoso, I. Santana, R. H. Swerdlow, and C. R. Oliveira, "Mitochondria dysfunction of Alzheimer's disease cybrids enhances A $\beta$ toxicity," Journal of Neurochemistry, vol. 89, no. 6, pp. 1417-1426, 2004.

[267] W. D. Parker, N. J. Mahr, C. M. Filley et al., "Reduced platelet cytochrome c oxidase activity in Alzheimer's disease," Neurology, vol. 44, no. 6, pp. 1086-1090, 1994.

[268] E. M. Mutisya, A. C. Bowling, and M. F. Beal, "Cortical cytochrome oxidase activity is reduced in Alzheimer's disease," Journal of Neurochemistry, vol. 63, no. 6, pp. 21792184, 1994.

[269] S. J. Kish, C. Bergeron, A. Rajput et al., "Brain cytochrome oxidase in Alzheimer's disease," Journal of Neurochemistry, vol. 59, no. 2, pp. 776-779, 1992.

[270] R. E. Davis, S. Miller, C. Herrnstadt et al., "Mutations in mitochondrial cytochrome $\mathrm{c}$ oxidase genes segregate with late-onset Alzheimer disease," Proceedings of the National Academy of Sciences of the United States of America, vol. 94, no. 9, pp. 4526-4531, 1997.
[271] R. H. Swerdlow, J. K. Parks, D. S. Cassarino et al., "Cybrids in Alzheimer's disease: a cellular model of the disease?" Neurology, vol. 49, no. 4, pp. 918-925, 1997.

[272] J. Valla, L. Schneider, T. Niedzielko et al., "Impaired platelet mitochondrial activity in Alzheimer's disease and mild cognitive impairment," Mitochondrion, vol. 6, no. 6, pp. 323330, 2006.

[273] R. Castellani, K. Hirai, G. Aliev et al., "Role of mitochondrial dysfunction in Alzheimer's disease," Journal of Neuroscience Research, vol. 70, no. 3, pp. 357-360, 2002.

[274] H. Umegaki, "Pathophysiology of cognitive dysfunction in older people with type 2 diabetes: vascular changes or neurodegeneration?" Age and Ageing, vol. 39, no. 1, Article ID afp211, pp. 8-10, 2009.

[275] N. Rasgon and L. Jarvik, "Insulin resistance, affective disorders, and Alzheimer's disease: review and hypothesis," Journals of Gerontology A, vol. 59, no. 2, pp. 178-183, 2004.

[276] R. Peila, B. L. Rodriguez, and L. J. Launer, "Type 2 diabetes, APOE gene, and the risk for dementia and related pathologies: the Honolulu-Asia Aging Study," Diabetes, vol. 51, no. 4, pp. 1256-1262, 2002.

[277] A. Ott, R. P. Stolk, F. Van Harskamp, H. A. P. Pols, A. Hofman, and M. M. B. Breteler, "Diabetes mellitus and the risk of dementia: the Rotterdam study," Neurology, vol. 53, no. 9, pp. 1937-1942, 1999.

[278] V. Rhein and A. Eckert, "Effects of Alzheimer's amyloid-beta and tau protein on mitochondrial function-role of glucose metabolism and insulin signaling," Archives of Physiology and Biochemistry, vol. 113, pp. 131-141, 2007.

[279] J. Janson, T. Laedtke, J. E. Parisi, P. O’Brien, R. C. Petersen, and P. C. Butler, "Increased risk of type 2 diabetes in Alzheimer disease," Diabetes, vol. 53, no. 2, pp. 474-481, 2004.

[280] S. M. De La Monte and J. R. Wands, "Molecular indices of oxidative stress and mitochondrial dysfunction occur early and often progress with severity of Alzheimer's disease," Journal of Alzheimer's Disease, vol. 9, no. 2, pp. 167-181, 2006.

[281] N. Lester-Coll, E. J. Rivera, S. J. Soscia, K. Doiron, J. R. Wands, and S. M. De La Monte, "Intracerebral streptozotocin model of type 3 diabetes: relevance to sporadic Alzheimer's disease," Journal of Alzheimer's Disease, vol. 9, no. 1, pp. 1333, 2006.

[282] E. J. Rivera, A. Goldin, N. Fulmer, R. Tavares, J. R. Wands, and S. M. De La Monte, "Insulin and insulin-like growth factor expression and function deteriorate with progression of Alzheimer's disease: link to brain reductions in acetylcholine," Journal of Alzheimer's Disease, vol. 8, no. 3, pp. 247268, 2005.

[283] E. Steen, B. M. Terry, E. J. Rivera et al., "Impaired insulin and insulin-like growth factor expression and signaling mechanisms in Alzheimer's disease-is this type 3 diabetes?" Journal of Alzheimer's Disease, vol. 7, no. 1, pp. 63-80, 2005.

[284] L. Frölich, D. Blum-Degen, P. Riederer, and S. Hoyer, "A disturbance in the neuronal insulin receptor signal transduction in sporadic Alzheimer's disease," Annals of the New York Academy of Sciences, vol. 893, pp. 290-293, 1999.

[285] M. Townsend, T. Mehta, and D. J. Selkoe, "Soluble A $\beta$ inhibits specific signal transduction cascades common to the insulin receptor pathway," Journal of Biological Chemistry, vol. 282, no. 46, pp. 33305-33312, 2007.

[286] W. Q. Zhao, F. G. De Felice, S. Fernandez et al., "Amyloid beta oligomers induce impairment of neuronal insulin receptors," FASEB Journal, vol. 22, no. 1, pp. 246-260, 2008. 
[287] C. J. Phiel, C. A. Wilson, V. M. Y. Lee, and P. S. Klein, "GSK$3 \alpha$ regulates production of Alzheimer's disease amyloid- $\beta$ peptides," Nature, vol. 423, no. 6938, pp. 435-439, 2003.

[288] L. Ho, W. Qin, P. N. Pompl et al., "Diet-induced insulin resistance promotes amyloidosis in a transgenic mouse model of Alzheimer's disease," The FASEB Journal, vol. 18, no. 7, pp. 902-904, 2004.

[289] S. Freude, M. M. Hettich, C. Schumann et al., "Neuronal IGF-1 resistance reduces $\mathrm{A} \beta$ accumulation and protects against premature death in a model of Alzheimer's disease," FASEB Journal, vol. 23, no. 10, pp. 3315-3324, 2009.

[290] E. Carro, J. L. Trejo, C. Spuch, D. Bohl, J. M. Heard, and I. Torres-Aleman, "Blockade of the insulin-like growth factor I receptor in the choroid plexus originates Alzheimer'slike neuropathology in rodents: new cues into the human disease?" Neurobiology of Aging, vol. 27, no. 11, pp. 16181631, 2005.

[291] J. L. Trejo, E. Carro, E. Garcia-Galloway, and I. TorresAleman, "Role of insulin-like growth factor I signaling in neurodegenerative diseases," Journal of Molecular Medicine, vol. 82, no. 3, pp. 156-162, 2004.

[292] J. L. Trejo, E. Carro, C. Lopez-Lopez, and I. Torres-Aleman, "Role of serum insulin-like growth factor I in mammalian brain aging," Growth Hormone and IGF Research, vol. 14, pp. S39-S43, 2004.

[293] E. Planel, Y. Tatebayashi, T. Miyasaka et al., "Insulin dysfunction induces in vivo tau hyperphosphorylation through distinct mechanisms," Journal of Neuroscience, vol. 27, no. 50, pp. 13635-13648, 2007.

[294] M. Schubert, D. P. Brazil, D. J. Burks et al., "Insulin receptor substrate-2 deficiency impairs brain growth and promotes tau phosphorylation," Journal of Neuroscience, vol. 23, no. 18, pp. 7084-7092, 2003.

[295] M. Hong and V. M. Y. Lee, "Insulin and insulin-like growth factor-1 regulate tau phosphorylation in cultured human neurons," Journal of Biological Chemistry, vol. 272, no. 31, pp. 19547-19553, 1997.

[296] A. Jämsä, K. Hasslund, R. F. Cowburn, A. Bäckström, and M. Vasänge, "The retinoic acid and brain-derived neurotrophic factor differentiated SH-SY5Y cell line as a model for Alzheimer's disease-like tau phosphorylation," Biochemical and Biophysical Research Communications, vol. 319, no. 3, pp. 993-1000, 2004.

[297] M. Lesort and G. V. W. Johnson, "Insulin-like growth factor1 and insulin mediate transient site-selective increases in tau phosphorylation in primary cortical neurons," Neuroscience, vol. 99, no. 2, pp. 305-316, 2000.

[298] C. Benedict, W. H. Frey, H. B. Schioth, B. Schultes, J. Born, and M. Hallschmid, "Intranasal insulin as a therapeutic option in the treatment of cognitive impairments," Experimental Gerontology, vol. 46, no. 2-3, pp. 112-115, 2011.

[299] M. A. Reger, G. S. Watson, P. S. Green et al., "Intranasal insulin improves cognition and modulates $\beta$-amyloid in early AD," Neurology, vol. 70, no. 6, pp. 440-448, 2008.

[300] M. A. Reger, G. S. Watson, W. H. Frey et al., "Effects of intranasal insulin on cognition in memory-impaired older adults: modulation by APOE genotype," Neurobiology of Aging, vol. 27, no. 3, pp. 451-458, 2006.

[301] S. Craft, L. D. Baker, T. J. Montine et al., "Intranasal insulin therapy for Alzheimer disease and amnestic mild cognitive impairment: a pilot clinical trial," Archives of Neurology, vol. 69, no. 1, pp. 29-38, 2012.

[302] M. E. Risner, A. M. Saunders, J. F. B. Altman et al., "Efficacy of rosiglitazone in a genetically defined population with mild-to-moderate Alzheimer's disease," Pharmacogenomics Journal, vol. 6, no. 4, pp. 246-254, 2006.

[303] G. S. Watson, B. A. Cholerton, M. A. Reger et al., "Preserved cognition in patients with early Alzheimer disease and amnestic mild cognitive impairment during treatment with rosiglitazone: a preliminary study," American Journal of Geriatric Psychiatry, vol. 13, no. 11, pp. 950-958, 2005.

[304] G. M. Salituro, F. Pelaez, and B. B. Zhang, "Discovery of a small molecule insulin receptor activator," Recent Progress in Hormone Research, vol. 56, pp. 107-126, 2001. 


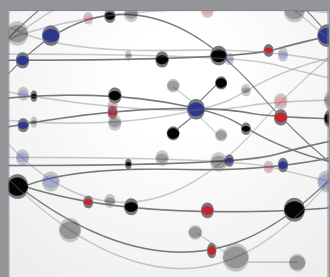

The Scientific World Journal
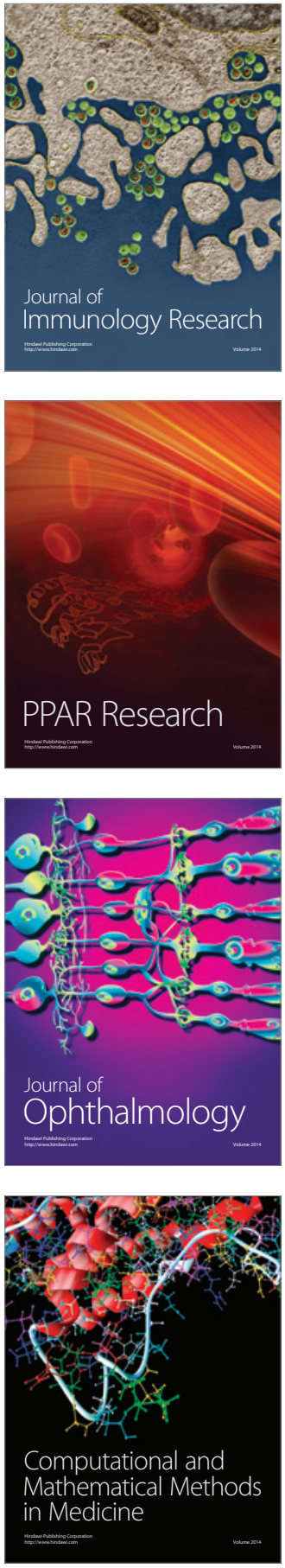

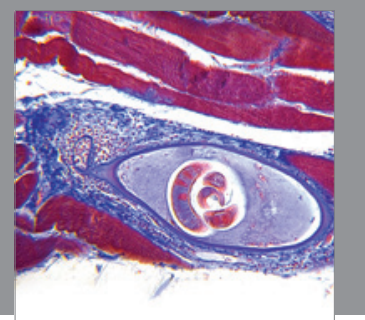

Gastroenterology

Research and Practice
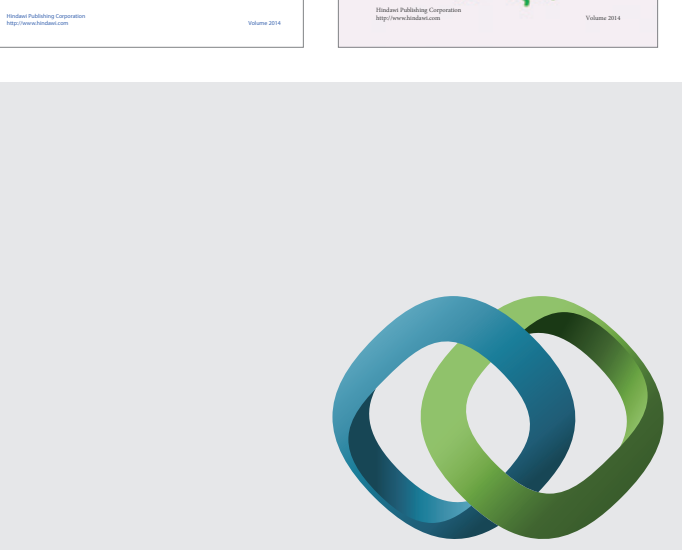

\section{Hindawi}

Submit your manuscripts at

http://www.hindawi.com
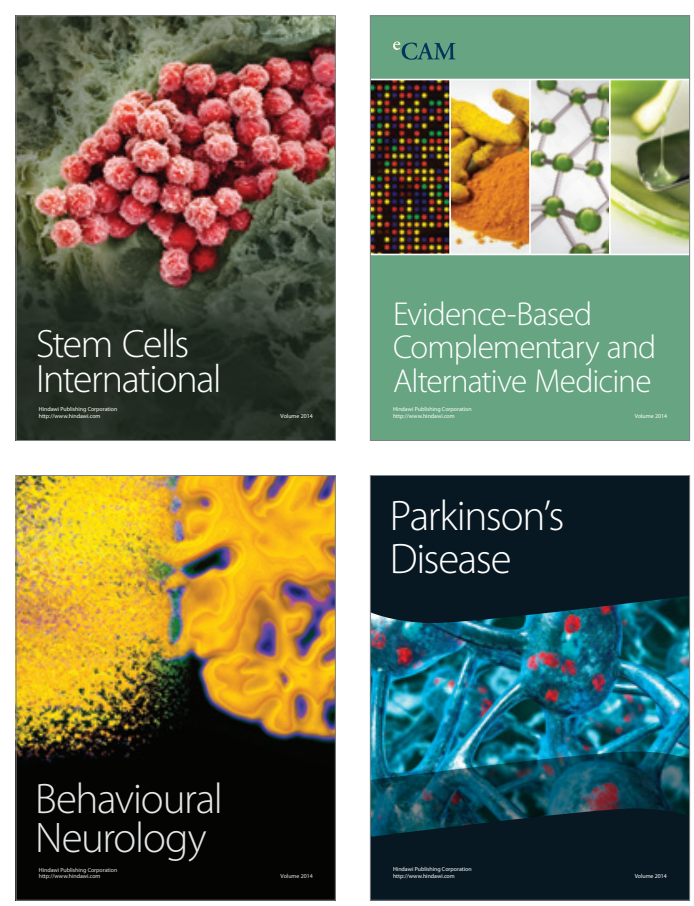

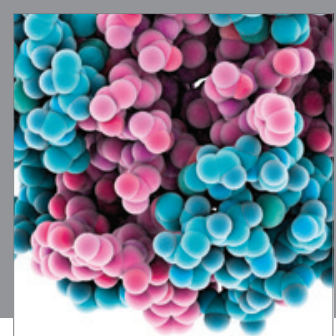

Journal of
Diabetes Research

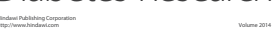

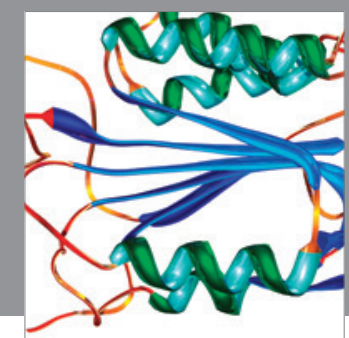

Disease Markers
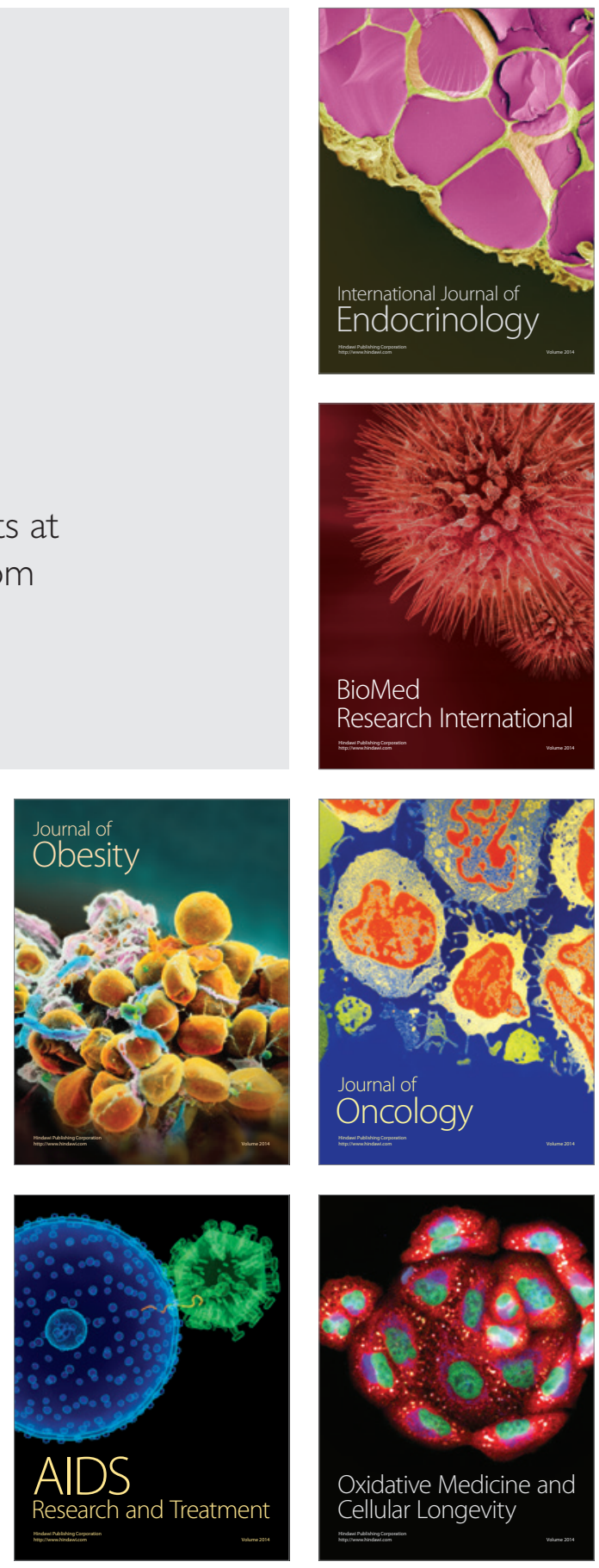